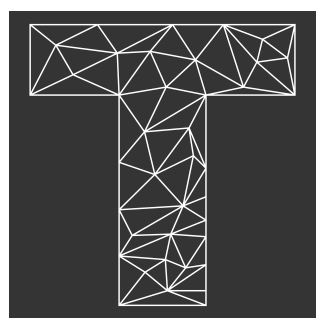

\title{
DESANDANDO LOS ENTRAMADOS IDENTITARIOS EN EL COMPLEJO HABITACIONAL SOLDATI, BUENOS AIRES, ARGENTINA
}

Revista Trama

Volumen 9, número 1

Enero - Junio 2020

Páginas 53-98

ISSN: 1659-343X

https://revistas.tec.ac.cr/trama
Untravelling The Identity Framework In The Soldati Housing Complex, Buenos Aires, Argentina

Anabella Moglia ${ }^{1}$

Moglia, A. (2020). Desandando los entramados identitarios en el Complejo Habitacional Soldati, Buenos Aires, Argentina. Trama, Revista de ciencias sociales y humanidades, Volumen 9, (1), Enero-Junio, págs. 53-98.

DOI: https://doi.org/10.18845/tramarcsh.v9i1.5269

1. Maestra y educadora popular, estudiante de Ciencias Antropológicas. Universidad de Buenos Aires. Buenos Aires, Argentina. Facultad de Filosofía y Letras. Código postal: Hidalgo 1039 - 1 “ 'D”.

Correo electrónico: anabellamoglia@gmail.com ORCID: https://orcid.org/0000-0002-3648-6802 


\section{Resumen}

Desde una aproximación socio-espacial que se basa en referentes teóricos y metodológico de la geografía y la antropológica crítica, este trabajo se propone abordar las temáticas de la vulnerabilidad y las identidades que se trazan alrededor de las marginalidades en el Barrio de Soldati, cordón sur de la Ciudad Autónoma de Buenos Aires. Para ello me abocaré al surgimiento de los Complejos Habitacionales de Soldati (CHS), intentaré dar cuenta de los cambios surgidos a partir de la planificación de los CHS en un contexto histórico determinado, y cómo el devenir de otras coyunturas influyeron en el transitar y el estigma que pesa sobre este barrio. En este sentido, reflexionaré acerca del tejido social que allí se entrama, abordando el ethos de "ser de Soldati" y el habitus que se fue construyendo. Mi hipótesis es que ambos se desarrollaron a partir de una fuerte cohesión interna, producto de una expulsión y marginalidad explícita y geográfica "externa" al barrio. Para concluir, intentaré dar cuenta de la fuerte incidencia de las políticas públicas en materia de mercado inmobiliario, la gentrificación como objetivo de la actual gestión del Gobierno de la Ciudad de Buenos Aires y la repercusión dentro del CHS a la hora de la reconfiguración de las identidades y pertenencia al barrio, y la dinámica surgida alrededor de la relación con el resto de la metrópoli. Para el análisis utilizaré mi trayectoria en el barrio a partir de trabajar en una institución educativa, entrevistas a dos vecinas del complejo, el uso y comparación de las fotografías, tomas satelitales y mapas extraídos de internet.

Palabras clave: cartografía; gueto; políticas públicas; segregación.

\section{Abstract}

From a socio-spatial approach based on theoretical and methodological references of geography and critical anthropology, this essay aims to address the issues of vulnerability and the identities shaped around marginality in the Villa Soldati neighbourhood, in the southern area of the Autonomous City of Buenos Aires. In order to do this, I will first focus on the emergence of the Soldati Housing Complexes (SHC), I will attempt to describe the changes that arose from the planning of the SHC in a specific historical context, and how the development of other factors influenced life in this neighbourhood and the stigma attached to it. In this sense, I will reflect upon the neighbourhood's social fabric, addressing the ethos of "being from Soldati" and the habitus built over time. My hypothesis is that both developed around a strong sense of internal cohesion, that is the product of an explicit geographical expulsion and marginality, "external" to the neighbourhood. Finally, I will attempt to account for the strong influence of real estate-oriented public policy, gentrification as an objective of the current Buenos Aires city administration and its impact on the SHC in terms of the re-shaping of the identities and sense of belonging within the neighbourhood, as well as the dynamics that shape the relationship with the rest of the city. For this analysis, I will draw upon my experience working at an educational institution and I will use interviews with two residents of the housing complex as well as comparisons between photographs, satellite pictures and maps. In the summary, I reflect back upon my initial hypothesis and I also outline a tension and a contradiction between that identity built upon the idea of an "outside" and the mutual recognition.

Keywords: cartography; ghetto; public policy; segregation. 


\section{INTRODUCCIÓN}

El siguiente artículo surgió a partir de transitar el barrio de Villa Soldati, desde mi inserción como docente del jardín comunitario maternal El Globo Rojo (institución educativa destinada a niños y niñas desde los 45 días hasta los 2 años inclusive) que se encuentra en la intersección de las calles Mariano Acosta y Avenida Roca, a pocos metros del Riachuelo ${ }^{2}$ y frente a los edificios del Complejo Habitacional Soldati (CHS), conocidos popularmente como "los edificios de colores".

Durante el tiempo transitado, fui comprendiendo y elaborando algunos lineamientos de posibles códigos interpersonales, que siempre se mantienen tácitos y de manera informal, pero que van tomando forma en las prácticas que se conllevan. A raíz de ir desandando mi participación y observación allí dentro, pude ir esbozando algunas líneas que acompañan la idea principal del trabajo: cómo a partir de un confinamiento espacial del CHS y sus habitantes, se fueron desenvolviendo prácticas y acciones que dan cuenta de un hábitus instalado y reproducido. Y cómo éste, a su vez, es el generador de un ethos entre quienes viven y habitan allí. Esta fuerte cohesión interna, se puede ver representada en expresiones verbales más coloquiales y de índole cercana entre vecinos, y miradas suspicaces y retraimiento en algunos comportamientos corporales para con quienes vienen de "afuera".

Sin embargo, esa construcción identitaria no está desapegada de la incidencia que existe por fuera del complejo, a través de tipificaciones construidas por el resto de la vecindad de Villa Soldati, como así también a través de modelos negativos y estigmas que devienen del resto de la metrópoli.

Del mismo modo, intentaré dar cuenta la participación activa en materia de políticas públicas que conllevan al CHS a ocupar un lugar relegado socio-espacial, que por un lado fue heredado y por otro es construido/reproducido por sus mismos habitantes. La construcción de ese ethos, se puede definir como opuestos entre el pasaporte de circulación y reconocimiento mutuo, y estigma segregatorio.

2. El Río Matanza-Riachuelo atraviesa localidades de la zona sur y oeste del Gran Buenos Aires y de la zona sur de la Ciudad Autónoma de Buenos Aires. En su último tramo, antes de su desembocadura en el Río de la Plata, es conocido como Riachuelo. 


\section{METODOLOGÍA}

A partir de mi inserción en el proyecto educativo fui buscando la manera de ir desplegando la matriz y parámetros que conllevaba a que se generara este rasgo tan arraigado y patente, como lo es la identidad del vecino de Soldati. Desde una perspectiva contrahegemónica, el proyecto educativo que llevamos a cabo en El Globo Rojo intenta resguardar los tiempos de los niños y niñas, en sus períodos de inicio, adaptaciones, tránsitos y la construcción del vínculo de confianza que es el cimiento de nuestra acción educativa y de crianza conjunta con las familias.

En el mismo espacio físico, conocido como "el galpón", donde se encuentra este jardín comunitario, también funcionan una biblioteca popular infantil abierta al barrio, un comedor comunitario y una cooperativa de higiene urbana, que prestan servicios de lunes a viernes. Todos pertenecen a una organización social y territorial llamada Movimiento Popular La Dignidad, pero sólo la institución educativa tiene un convenio de co-gestión con el Ministerio de Educación del Gobierno de la Ciudad de Buenos Aires. Esta co-gestión implica una tensión constante entre lo que mandata el Ministerio y los espacios de autonomía que conformamos como espacio autogestionado.

Esta modalidad de gestión asociada implica que el Estado sólo garantiza el salario de las docentes, mientras que la comunidad educativa (educadoras y familias) debe garantizar el sostenimiento de los materiales didácticos, la infraestructura y su mantenimiento. Para ello, el jardín se organiza conjuntamente con las familias mediante asambleas quincenales en la que se deciden cuestiones relacionadas al sostenimiento del espacio del "galpón", desde la limpieza y desinfección del mismo hasta festivales para recaudar fondos para los insumos y materiales necesarios.

Formo parte de esta experiencia desde 2013, lo que me ha permitido interactuar con los diversos actores que transitan por el predio en el que funciona el jardín, como así también con las familias que fueron pasando por este proyecto, muchas de las cuales pertenecen al CHS.

Con el correr del tiempo mi figura allí dentro fue virando. Comencé siendo simplemente una educadora contratada por el Estado, para luego convertirme en parte integral del proyecto. Este viraje implicó también que mis "pasos" fueran tomando otra impronta y lugar, ya como 
una "referente" más del espacio educativo, a quienes vecinos y vecinas identifican de esta manera cuando se me acercan al cruzarme por las cuadras del barrio para alguna consulta referida "al Globo".

Hacia dentro del galpón, mi participación también fue cambiando. Toda persona que se acerca por primera vez puede sentir esa "lejanía" de no pertenecer, ya que hay códigos muy establecidos que condicionan las interacciones con quienes vienen "de afuera" del barrio. Sin embargo, con el paso del tiempo, un cambio clave que se suscitó respecto de mi presencia en el galpón fue que las personas que realizan sus actividades allí comenzaron a sostener diálogos informales delante mío; esto me hizo sentir que ya pasaba desapercibida, que ya era "una más" allí dentro y que me estaba permitido presenciar - y decodificar- esos intercambios. Esto también me permitió conocer las relaciones entre vecinos, las relaciones de parentesco y los códigos que se manejan. Con el tiempo, y a medida que se interactúa y se comprenden las lógicas que rigen estas relaciones, se va revelando una idea de que "lo que sucede en el barrio, sucede en el galpón", es decir, que las tensiones, suspicacias, alianzas y contradichos que se suscitan dentro de los CHS, también se reflejan en los espacios que funcionan en el predio.

A pesar de la evolución de mi rol dentro del galpón, nunca dejé de sentirme "extranjera" en el barrio. En contadas ocasiones tuve que cruzar la calle Mariano Acosta y adentrarme en los CHS, generalmente para llevar a alguno de los niños del jardín a su casa en uno de los edificios del complejo. En estas ocasiones, sentía que el uniforme de maestra me confería un cierto resguardo, autoridad -relativa y contradictoria- e identidad provisoria allí dentro y que sólo era temporaria. Esta sensación era corroborada por las miradas suspicaces de los transeúntes y sus actitudes desconfiadas, que me siguieron confirmando el estado de "extranjera" que tenía allí.

Sentir que mi figura era disonante fue una de las inquietudes que me acompañó desde el primer día y perdura hasta hoy. Este proceso me llevó a preguntarme acerca de la configuración de la identidad de los vecinos del barrio y la manera en que se perciben en relación al resto de los habitantes de la ciudad. Mi hipótesis, que intenta responder a esta pregunta, es que los CHS se configuran como un gueto dentro del 
cual existe un habitus que propicia la formación de un ethos, en una retroalimentación mediada por la marginalidad y la segregación.

Para realizar este análisis, me ubico entonces en el rol de observadora participante y tomo el concepto de Bourdieu (2003) de "objetivación participante". La sensación de "extrañeza" nos permite, como analistas de la realidad social, reflexionar sobre nuestro propio rol y lugar en el campo, así como "no ignorar las condiciones sociales de esas preconstrucciones y los agentes sociales que las producen" (Bourdieu, 2003; p.88). Ponerme en el foco del análisis y ahondar sobre las sensaciones que (me) genera el campo -generalmente extraño a todo investigador- es uno de mis principales puntos para mantener la rigurosidad como sujeto de análisis, ya que:

(...) de lo que se trata el hecho de objetivar, en efecto, no es del antropólogo haciendo el análisis antropológico de un mundo ajeno, sino del mundo social que ha hecho el antropólogo y la antropología consciente o inconsciente que él compromete en su práctica antropológica; no solamente su medio de origen, su posición y su trayectoria en el espacio social, su pertenencia y sus adhesiones sociales y religiosas, su edad, su sexo, su nacionalidad (...) dependen muy estrechamente de la posición que él ocupa en su universo profesional (...) con sus tradiciones, sus particularismos nacionales, sus hábitos de pensamiento (...) sus rituales, sus valores (Bourdieu, 2003, p.89).

Lejos de querer reproducir una mirada distante o ajena al lugar, el desafío de mi análisis radica en la posibilidad de apoyarme en el bagaje asimilado desde mis incipientes pasos por el jardín y el galpón, pudiendo utilizarlo como insumo que me permita ir desandando y decodificando los interrogantes que fueron surgiendo a lo largo de mis vivencias.

Sin embargo, está claro que el análisis no sería completo si no incluyera la mirada de los sujetos que son protagonistas de estas construcciones identitarias. A este fin, incorporé como técnica de recolección de datos las entrevistas con dos vecinas del barrio Soldati: María y Celeste. María tiene 70 años y es vecina del barrio desde el año 1978. Llegó a vivir allí por un desalojo que sufrió cuando ocupaba tierras 
del Parque Interama (hoy Parque de la Ciudad) y por medio del contacto de su patrón que era militar, accedió a uno de los créditos de la Secretaría de Vivienda. Actualmente trabaja como camarera del jardín: es quien se encarga de recibir la comida que llega, acomodar el mobiliario para que funcione el almuerzo de los infantes y saber las particularidades de cada niño y niña referidas a la alimentación y su cuidado. Es una compañera más del colectivo de educadoras y con quien trabajo desde mi llegada ahí. Todo este tiempo de trabajo conjunto me dio una cercanía y confianza, lo cual me permitió recurrir a ella como fuente para este trabajo.

Por su parte Celeste, de 34 años, vive en el barrio desde que nació, debido a que su madre accedió a un crédito por ser empleada estatal. Ella fue familia del jardín con sus dos hijos menores. Se acercó por primera vez en 2014 y hasta el día de hoy mantiene relación con el galpón. Desde 2018 comenzó a formar parte como militante de la organización, participando en la biblioteca popular que funciona en el predio.

Una de las características que más me impactó -y me sigue impactando- es la fisonomía del barrio, compuesta por el espacio geográfico, en el cual conviven viviendas de casas bajas -que son las primeras construcciones alrededor de la estación de tren- terrenos fiscales ociosos, campos de deportes de clubes y escuelas, fábricas y depósitos de transporte de mercadería pesada y los edificios del Barrio Soldati que nos ocupa en este análisis, que fueron construidos como viviendas sociales en la década del '70. Todos estos componentes le dan una impronta particular que conlleva el "habitar" los diversos espacios en momentos del día y la semana de modos diferentes, construyendo una escenografía propia. Este escenario está fundado sobre los cimientos de "poblar" un espacio dentro del perímetro de la Ciudad Autónoma de Buenos Aires (CABA), pero intentando generar una pseudo autonomía en el funcionamiento de dichos complejos. La propuesta de la integración de una determinada población no sólo radica en establecerlos en un espacio determinado, sino que implica analizar cuáles son las vías de acceso a los núcleos neurales de una urbe. Si la accesibilidad no está garantizada porque hay déficits en las mismas o se intenta autoabastecer sólo en algunas ramas -como comercios, escuelas, plazas- pero con demandas sin saciar, existe una paradoja en poder llevar a cabo la plena ciudadanía. 
De esta manera, la constitución del nuevo barrio fue acompañada por dos grandes opuestos: por un lado, emplazar esta edificación reubicando a una población ya existente, pero logrando que la misma tenga abastecimiento dentro de ese perímetro.

Para abordar el paisaje tan particular de los CHS y zonas aledañas, me apoyo en el uso de mapas, imágenes satelitales y fotografías. Considero que estos insumos son un soporte imprescindible para describir esta zona periférica de la Ciudad Autónoma de Buenos Aires. Son una contribución complementaria al desarrollo del análisis, pero que también hablan por sí mismas. Las fotografías que aparecen en el trabajo, intentaron captar los momentos del día en los que transito, como así también dar cuenta de esa desolación que intento transmitir y parte constitutiva de ese "espíritu propio" que forma parte de los habitantes del lugar. 


\section{REFERENTES CONCEPTUALES}

En términos conceptuales, partiré de la perspectiva del derecho a la ciudad que establece David Harvey (2014) y lo complementaré con los conceptos vertidos en el artículo "Una cartografía simbólica de las representaciones sociales" de Boaventura De Sousa-Santos (1991). Ambos autores intentan dar cuenta de los modelos de concentración de poder, en distintos niveles. El primero lo aborda desde un sentido exclusivamente de concentración del capital y su inversión en el mercado inmobiliario y cómo este circuito genera monopolios y exclusión. El segundo, apunta a la configuración del status socioespacial a partir de la elaboración de los mapas, referencias e íconos en su construcción, que no son más que maneras arbitrarias con una intencionalidad política detrás. Mi objetivo es relacionar y poner en tensión la dialéctica llevada a cabo entre la producción de la tipificación de estos barrios en las periferias del sur de CABA y su estigmatización como necesidad -y causa- de la expulsión.

Luego intentaré relacionar cómo el concepto de "gueto" que propone Loïc Wacquant (2010), quien resignifica dicho término desde una mirada histórica, social, política, económica y cultural, como producto de esta ideología y planificación y organización de las ciudades modernas. El autor apela a un abordaje del gueto como un producto de la segregación espacial, pero no sólo en términos materiales, raciales o étnicos, sino también con factores "simbólicos", en el cual las políticas estatales tienen una clara influencia y son generadoras de los mismos. Tomaré de su desarrollo y de la mirada que hace de las "banlieues" ${ }^{3}$ parisinas, un modelo de análisis de las políticas capitalistas llevadas a cabo en las grandes urbes, como un fenómeno mundial en expansión.

Culminaré el desarrollo analizando las políticas llevadas a cabo desde la actual gestión del gobierno de la CABA y cómo éstas profundizaron un modelo de gentrificación, estableciendo políticas bien diferenciadas entre el centro y norte de la ciudad, y el sur de la misma.

3. Término francés para denominar a los suburbios. 


\section{APROXIMÁNDONOS A LA GEOGRAFÍA DEL BARRIO: LÍMITES Y CARACTERÍSTICAS}

Villa Soldati es uno de los cinco barrios que conforman el cordón sur de la CABA. De oeste a este se encuentran:Villa Riachuelo, Villa Soldati, Pompeya, Barracas y La Boca ${ }^{4}$. Todos ellos comparten el Riachuelo como límite al sur, el cual también divide la CABA de la Provincia de Buenos Aires. Este río se caracteriza por su alto nivel de contaminación a causa de desechos industriales y metales pesados. Cuando el cauce del río se ve interrumpido por una sudestada ${ }^{5}$, genera inundaciones en las márgenes del mismo y, por consiguiente, en los barrios que se hallan en ellas. Adicionalmente, a lo largo de la cuenca Matanza-Riachuelo se encuentran problemáticas "socio-sanitario-ambientales individuales, familiares y colectivas" relacionadas con la exposición excesiva a contaminantes del suelo, aire y agua, falta de acceso al agua potable y cloacas, disposición inadecuada de basura, presencia de plagas y vectores, actividades de riesgo ambiental, etc. (Acumar, 2019, p. 2-3)

Imagen 1. Localización de Villa Soldati. Barrios que contiene y distancia de los CHS del Riachuelo.

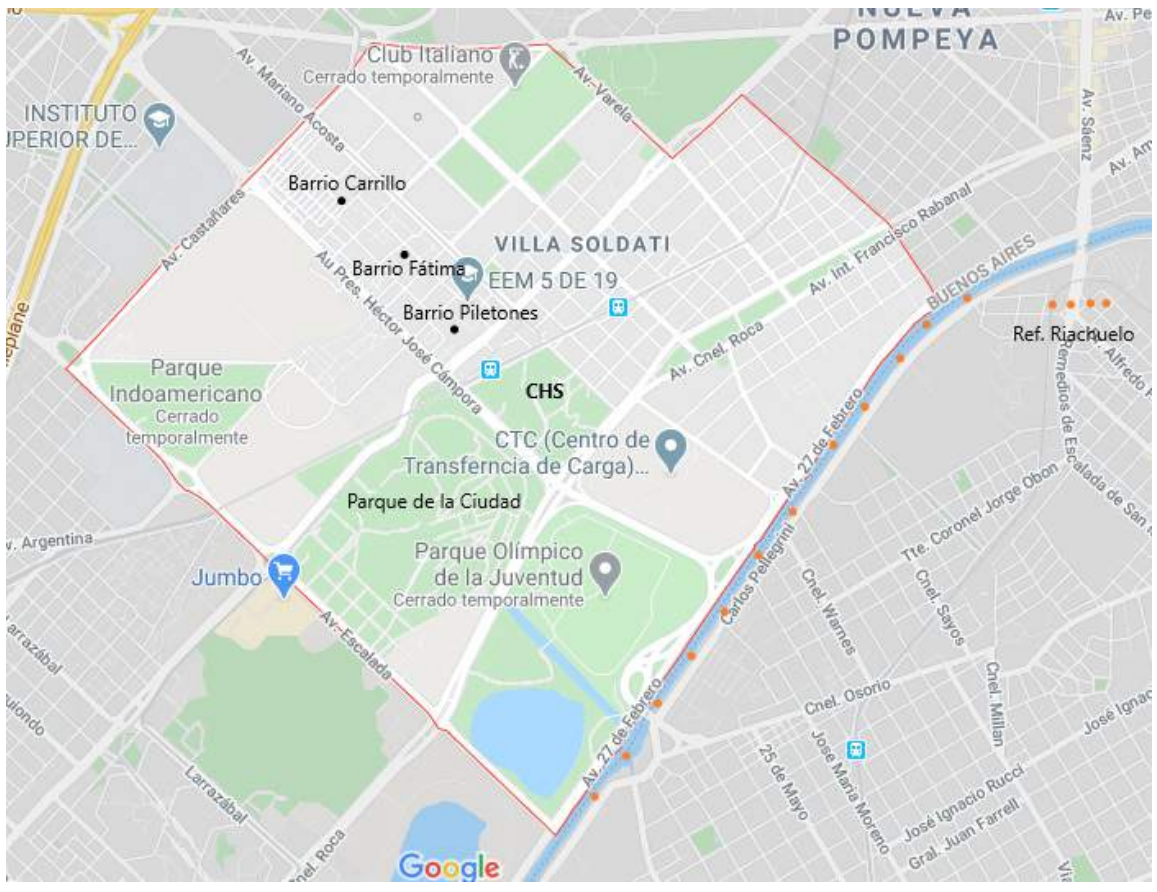

Fuente: GoogleMaps.

4. Mapa con detalles de los barrios de Buenos Aires extraído de la página oficial del Ministerio de Educación Nacional. http://mapoteca.educ.ar/.files/index.html.1.5.html

5. Vientos y tormentas muy fuertes que generan la subida del Río de La Plata, impidiendo el recorrido del caudal de agua del Riachuelo 
El vaho a "podredumbre" invade el aire, cuando existe viento que proviene del sudeste, como así también si la humedad es muy alta. Me parece importante destacar estas características, ya que son imperceptibles en la trascripción de la ubicación geográfica, pero son un elemento clave de la configuración socioespacial.

Según el mapa de la imagen 1, cerca de un tercio del espacio que ocupa Villa Soldati está compuesto de espacios verdes destinados a:

- Campos de deporte de escuelas, ONG's.

- Predios recreativos de fuerzas de seguridad.

- Centros deportivos pertenecientes a Clubes de Fútbol.

- Anexos de Clubes de Barrio.

- Entre otros.

Los dos tercios restantes están ocupados por grandes galpones de almacenamiento de containers o su contenido. La zona se convirtió en un centro de trasbordo de mercaderías pesadas, a partir de un nuevo diseño y planificación de la ciudad que ejecuta la gestión del PRO, el partido que gobierna ininterrumpidamente la CABA desde 2007, a través de las gestiones de Mauricio Macri (2007 - 2015) y Horacio Rodríguez Larreta (2015 - 2023). Así, gran parte de este territorio se encuentra dividido en predios delimitados por grandes paredones y alambrados que exceden, generalmente, los 100 o 200 metros habituales que hacen a una cuadra promedio en la CABA. Estas características modelan las calles y veredas de Soldati, haciendo de ellas un paisaje que oscila entre lo urbanizado, lo fabril y lo desolado. 
Imagen 2. "Centro de Trasbordo de Mercaderias". Intersección de la Av. Mariano Acosta y Av. Roca, un día hábil al mediodía.

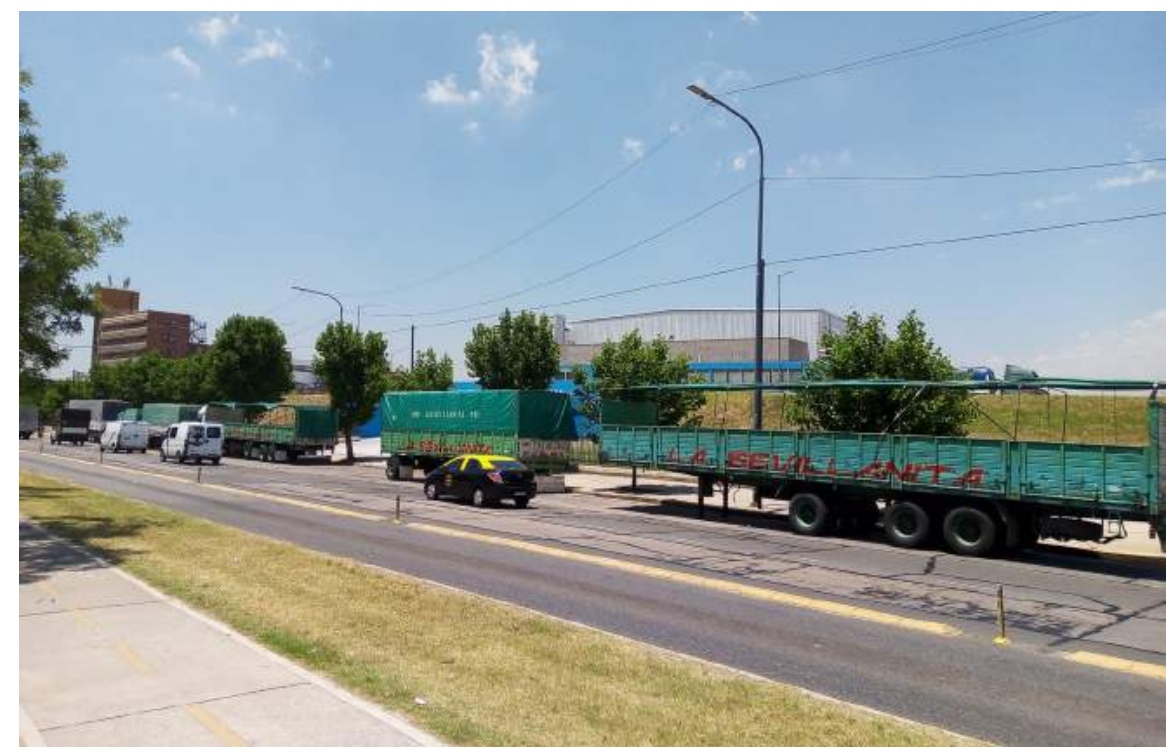

Fuente: Elaboración propia. Tomada en diciembre de 2019.

Imagen 3. "Playón Roca" misma intersección que la fotografía anterior, pero tomado desde enfrente.

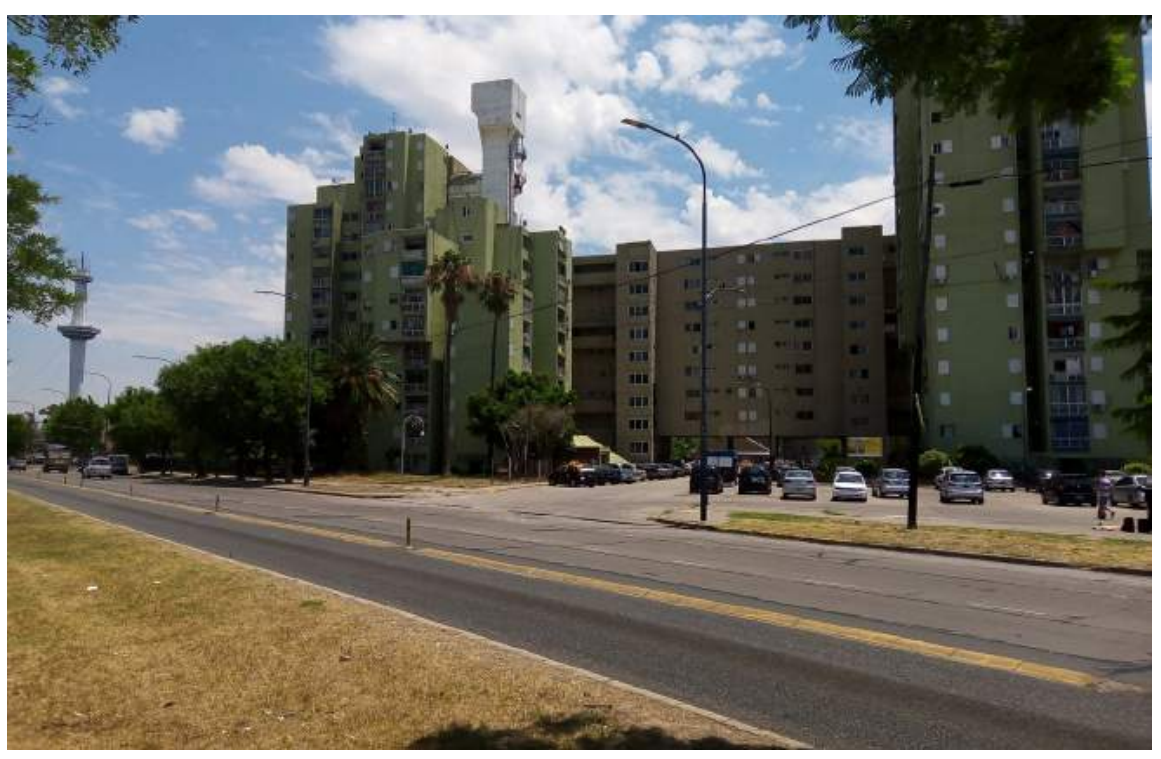

Fuente: Elaboración propia. Tomada en diciembre de 2019. 


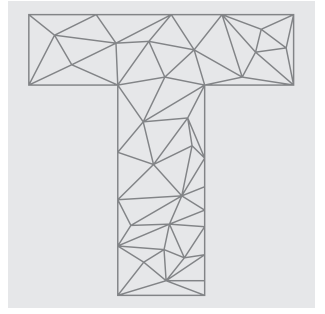

Anabella Moglia

Imagen 4. Barrio Fátima. Vías del Premetro. Coordenadas: Mariano Acosta y Pasaje José Batlle y Ordoñez.

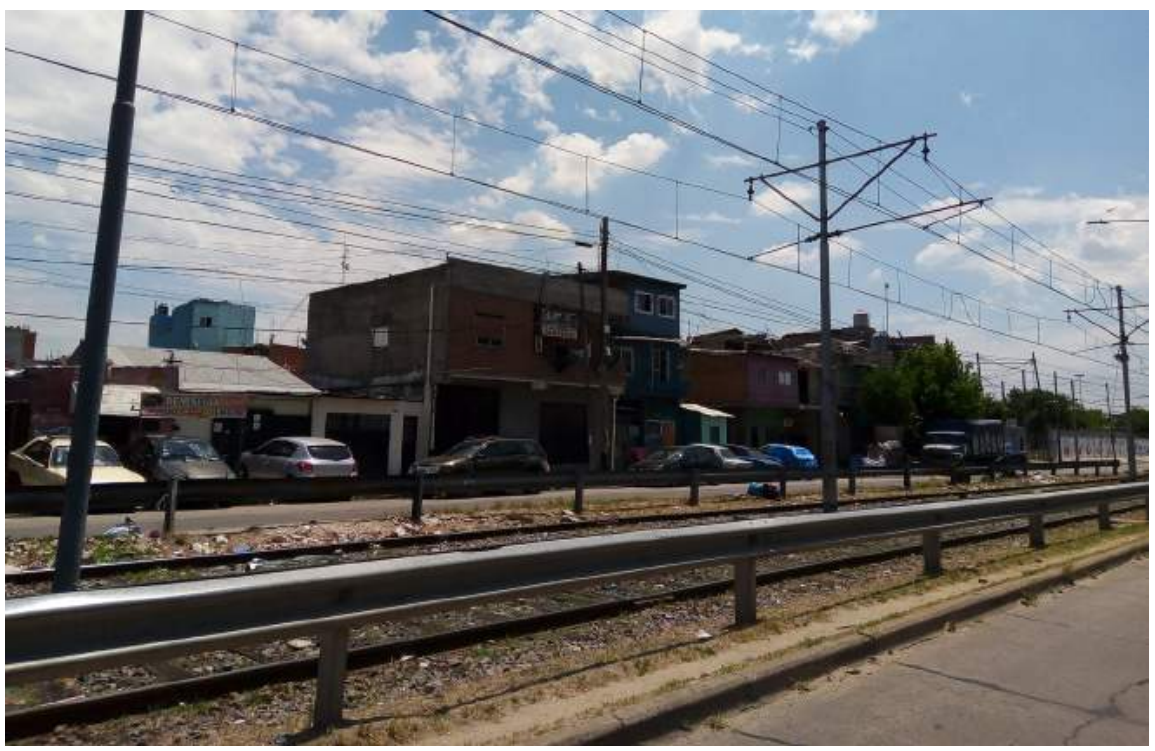

Fuente: Elaboración propia. Tomada en diciembre de 2019.

Imagen 5. "Barrio Fátima" Coordenadas: Mariano Acosta y Somellera.

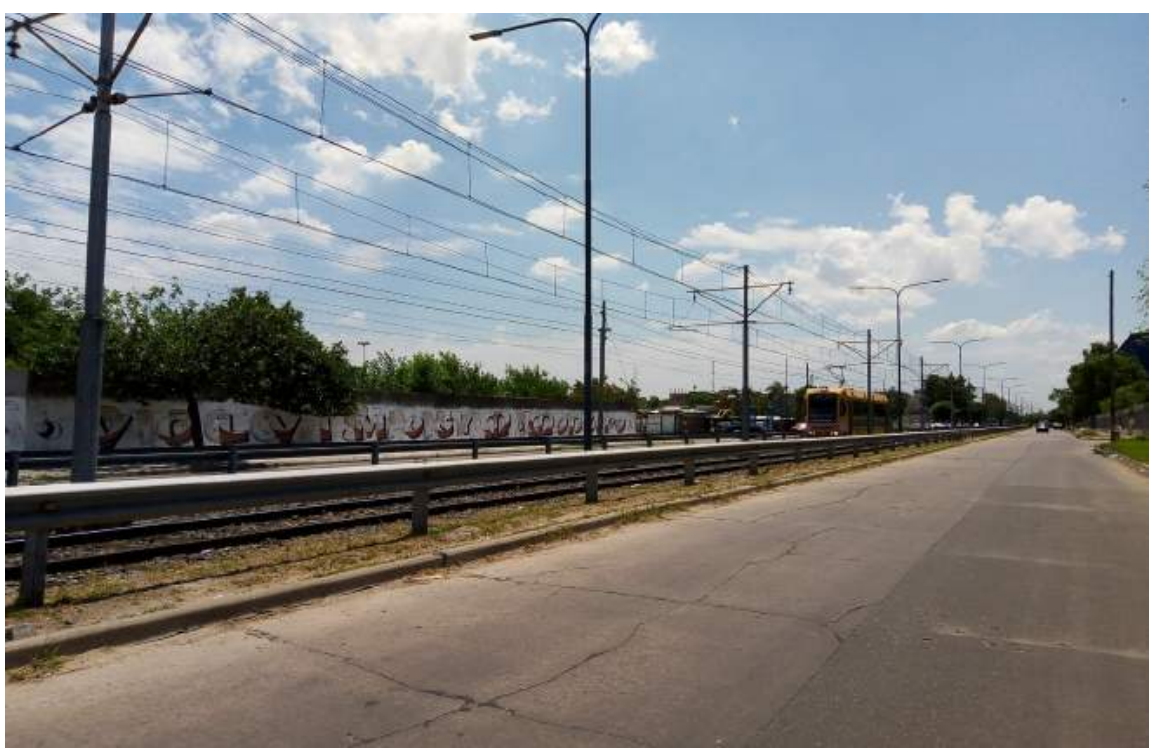

Fuente: Elaboración propia. Tomada en diciembre de 2019. 
La población está desigualmente distribuida dentro de estos límites, causando una irregularidad en el transitar y el habitar de las cuadras que constituyen dicho barrio.

Para adentrarme a lo que me concierne en este trabajo, me es indispensable hacer un breve recorrido histórico del surgimiento del complejo, como así también de su devenir y transformación en el desarrollo, ocupación y configuración de los años subsiguientes a su emplazamiento. 


\section{SURGIMIENTO DE UN NUEVO BARRIO: LAS MISCELÁNEAS DE LA POBLACIÓN}

Girola (2007) hace una presentación y análisis de la construcción de los monoblocks que se emplazan en las intersecciones de Mariano Acosta y Roca, con un objetivo claro: abordarlo desde una perspectiva socioantropológica, que dio en llamar "apropiación del espacio y la sociabilidad vecinal". La autora intenta explicar cómo dicho "espacio planificado" dista y se tensiona con el "espacio habitado".

El nacimiento de estas viviendas sociales se da a partir de una política de la Secretaría de Vivienda de la Nación, dentro del Plan de Erradicación de Villas de Emergencia (PEVE), entre los años 1964 y 1967, y fueron construidos entre los años 1973 y 1978. Cabe aclarar que en el mes de marzo de 1976 se produce un golpe de Estado que destituye al gobierno democrático, iniciándose uno de los capítulos más crueles y sangrientos de la historia argentina, por lo que la implementación, otorgamiento y escrituración de los departamentos, se realizó bajo el gobierno de facto. La entrega de escrituras, siguen en proceso hasta el día de hoy.

La nueva perspectiva con la cual se abordó la planificación urbana unía dos matrices: "el urbanismo funcionalista y la arquitectura moderna" (Girola, 2007, p. 136). El emprendimiento Barrio Soldati intentó:

- Dar la posibilidad de la vivienda propia a un gran conjunto de empleados estatales con créditos flexibles y tasas accesibles.

- La erradicación de sectores vulnerables que fueron desalojados de conventillos, tomas y pensiones, a raíz de una fuerte subida en los alquileres y re-diseño del área urbana ${ }^{6}$.

Esta diversidad de población -y de sus trayectorias habitacionales, en términos de la autora- implicó una diferenciación importante en el habitar de las nuevas unidades, como así también una heterogeneidad en la configuración de la nueva población que fue habitando un espacio relegado, pero a la vez, conformándose en la ciudad. El predio fue construido sobre 19 hectáreas, las cuales, hasta el momento de su edificación, estaban ociosas. Dentro del objetivo de estas viviendas, se encontraba la diagramación de locales, escuelas y un centro vecinal, con el fin de generar "una ciudad dentro de otra ciudad" (Girola, 2007, p. 139). La cuestión arquitectónica que imperaba en esos años confluía

6. Se sugiere ver documental acerca del Parque Interama/ Parque de la ciudad. Fernández, Magda 12/4/2016. “El Parque"You Tube. https://www.youtube.com/watch?v=gtsvqC-jw7l 
en la premisa: "orden social, a partir de un orden espacial". Es decir, los diversos bloques y pabellones, que se comunican a partir de escaleras y algunos puentes, tienen como finalidad ubicar en cada vivienda a una familia nuclear. De alguna manera, esa disposición espacial intenta generar una organización y control socio-espacial: por un lado, establecer las directrices que el modelo de organización social familiar burguesa demanda, en oposición a otras configuraciones más ligadas a sociedades pre-capitalistas, en las cuales los núcleos se forman a partir de lazos familiares extendidos. Así lo expresa un fragmento del PEVE, en Thomasz, A. (2014):

[...] el ex-habitante de villas de emergencia conserva aún pautas rurales, con poca adaptación a la vida urbana; es decir, con escaso nivel de relación e integración social tanto a escala grupal como vecinal. Es evidente entonces, que estamos ante una población de tipo y características particulares, con problemas que no son fáciles de superar (p. 281).

De esta manera, pensar las estrategias en materia de construcción, para fomentar la vinculación entre los vecinos, que venían con trayectorias de vivienda y laborales diversas, fue la clave y el objetivo de establecer espacios comunes, favoreciendo las relaciones para llevar a cabo la convivencia.

Esa convivencia se establece entre el transitar cotidiano por el predio, la perspectiva y proyecciones que se establecen sobre el campo a habitar, sus actividades cotidianas, laborales y familiares, y el uso concreto del espacio - privado y público. La heterogeneidad de la población, sus trayectorias van conformando un uso y habitus del predio que implican tensiones y distancias simbólicas en esas actividades. Girola (2007, p. 138) describe estos elementos de la siguiente manera: "...la mudanza fue vivida de modo diferente según la posición socioeconómica y cultural de cada uno de los entrevistados".

El diseño de estos edificios fue pensado para maximizar el espacio, para albergar alrededor de 17.880 personas (Girola, 2007, p. 136), generando porosidades en el intercambio del transitar en el nuevo predio, intraedificios y para con el resto de la ciudad. Por eso, cabe resaltar que no fue ingenuo el traslado y reubicación de este sector de la sociedad 
dentro de lo que es la Capital Federal -como en ese momento era denominada- sino que fue una apuesta política de posibilitar "fronteras simbólicas de transición", materializándose en intercambios alternados con el resto de la ciudad, algo así como "estar insertos, pero sin estarlo del todo". Con frontera quiero hacer mención a esos límites establecidos de manera tácitos e informales, pero que condicionan o moderan la práctica y las interrelaciones personales. Celeste comenta lo siguiente: "y a veces digo que el haber tenido amigos por fuera en otros lados (...) quizá sea una de las cosas que me salvó la vida, en alguna forma de decirlo". Y al repreguntarle qué quiere significar con el "fuera" responde: "De afuera del barrio (...) Al complejo de edificios y todo lo que conlleva vivir en un complejo de edificios". La entrevistada hace énfasis en que vivir en los CHS es muy particular y que hay diferencias con respecto a vivir en un barrio común

tiene un montón de cosas que no es lo mismo que vivir en Parque Patricios, ni siquiera te estoy hablando de Barrio Norte, te estoy hablando de Pompeya, Parque Patricios, no es lo mismo [en] Un montón de cosas que es distinto, y que pasa esto. Es la gente en realidad, que marca mucho esa diferencia también (Celeste). 


\section{VI. ¿DE QUÉ SE HABLA CUANDO SE DICE: "DERECHO A LA CIUDAD"?}

Pensar el derecho a la ciudad implica pensar la planificación, ocupación, distribución, uso y acceso a los distintos puntos y servicios de la ciudad. El diseño y la perspectiva a partir de los cuales está organizada la CABA están teñidos por una mirada eurocentrista y funcionalista de concebir las urbes. Al respecto, Topalov en Thomasz (2014) aporta: "Entre fines del siglo XIX y comienzos del XX, el urbanismo se configuró como ciencia y práctica de la planificación, como saber y dominio instrumental destinado a oficiar de "antídoto" contra los "males" de la ciudad moderna industrial (crecimiento rápido y desordenado, hacinamiento, falta de infraestructura)" (281). Los modelos implementados aquí, fueron importados del viejo continente.

En cuanto a referirse a la construcción de viviendas para albergar a la gran población trabajadora que creció frente a una metrópoli en desarrollo, agrega:

La edificación de viviendas de interés social con el formato del gran conjunto urbano constituyó una tendencia internacional que se registró primero en Europa y Estados Unidos (desde el período entreguerras y, con más ímpetu, durante la etapa de reconstrucción que siguió a la Segunda Guerra Mundial y al bum de natalidad de la década del sesenta) y luego en América Latina (...) Esta estructura de imponente aspecto es tributaria del legado de Le Corbusier y de los principios de la planificación urbana de corte técnico-funcionalista, con la cual se intentó, en el siglo XX, ordenar y controlar el espacio urbano y así disciplinar a la población que lo habitaba (Ortiz en Thomasz, 2014, pp 279/281).

Harvey (2014) nos adentra en el proceso de pensar las grandes ciudades modernas capitalistas y nos habla acerca de cómo ese sistema económico no sólo manda en la división social del trabajo, sino en el ordenamiento, en el diseño de los espacios y su población, que están sometidos a y dictaminados directamente por la lógica del mercado. Para este caso cita el modelo que Haussmann llevó a cabo en París, cuando éste innovó en la implementación de un diseño urbano bajo el supuesto de "beneficio público en nombre de la ciudadanía (...) y la renovación urbana" (p.37). Y cita a Engels: 
(...) la burguesía sólo dispone de un método para resolver a su modo el problema de la vivienda, esto es, de resolverlo de forma que se perpetúe, y este método se llama "haussmannización" [como yo lo denominaría] a la práctica de la apertura de brechas en los barrios obreros (Harvey. 2014. P.37/38).

Señala una paradoja, la cual no es más que la regla de oro que rige en esta dialéctica: las ciudades nacieron a partir de la concentración de población en una geografía limitada, y para que éstas se reproduzcan requieren del excedente que la misma población genera estando en ellas. Por supuesto que dicho organigrama no está libre de la clásica división de las clases: la burguesía y el proletariado. Pero en este caso, me interesa resaltar cómo cada una de ellas tiene "su" lugar en este espacio urbano.

Dentro del modelo establecido por Harvey (2014), la gentrificación es un concepto clave $-y$ a la vez consecuente- para complementar la lógica que me convoca en este trabajo. Es la diagramación, diseño y distribución de la población en espacios determinados, siguiendo la matriz del lineamiento de la estratificación de ese suelo urbano. De esta manera, se construye arbitraria y políticamente una división tácita y material del mismo, generando una revalorización del suelo que sirve a un doble propósito: fomentar la suba del valor de algunos sectores dentro de la ciudad en detrimento de otros y producir sectores, tipificaciones y estigmas que pesan sobre ellos, al (des)echarlos en dichos espacios. Esta lógica conlleva la expulsión de las poblaciones más vulnerables, de manera concreta y simbólica, y favorece el incremento del capital en manos cada vez más concentradas.

La concentración del excedente vierte en la cadena de producción inmobiliaria capitalista nuevos proyectos regidos por la lógica descrita. Es así que la generación de nuevos emprendimientos trae, indefectiblemente, mayor cantidad de expulsados para ser reubicados dentro de este direccionamiento y diseño de las ciudades modernas; fomentando así el aumento del valor de las tierras centralizadas en los epicentros urbanos.

Todo este proceso implica que"para hacer surgir la nueva geografía urbana del derrumbe de la antigua, se requiere siempre violencia." (Harvey, 2014, p. 28) 
Este modelo puede ser utilizado para analizar el complejo de viviendas de Villa Soldati. El mismo fue ideado para alojar a la población anteriormente descrita, con el doble objetivo de elevar el valor del suelo "liberado", permitiendo la circulación de nuevos capitales para el negocio inmobiliario ${ }^{7}$ y, a la vez, elevar el valor del suelo de los terrenos ociosos donde se emplazó el nuevo barrio, conformado en un gran porcentaje por personas desalojadas de sus viviendas anteriores y reubicadas en un espacio bien delimitado y concentrado. 


\section{DE LO MATERIAL A LO SIMBÓLICO}

Esta nueva forma de concebir a la ciudad moderna está acompañada por su directriz simbólica, en el nuevo diseño urbano. La producción, distribución y posterior conformación de los sectores en la "innovación" de la arquitectura y el urbanismo- está ligada a una nueva representación y tipificación de la población que ocupa y habita dichos espacios.

Santos (1991) nos aporta el rol que la cartografía esconde y genera, de manera arbitraria, intencional y complementaria, fundando íconos y símbolos en la constitución de los mapas. La "distorsión", uno de los ejes primordiales de la cartografía, es funcional a este nuevo redireccionamiento en la refundación de la ciudad moderna. Claro que esta distorsión no es equitativa para todos los puntos de la ciudad a cartografiar, sino que está sometida a una perspectiva funcional y capitalista.

Imagen 6. Captura de pantalla del perímetro en el que están emplazados los CHS.

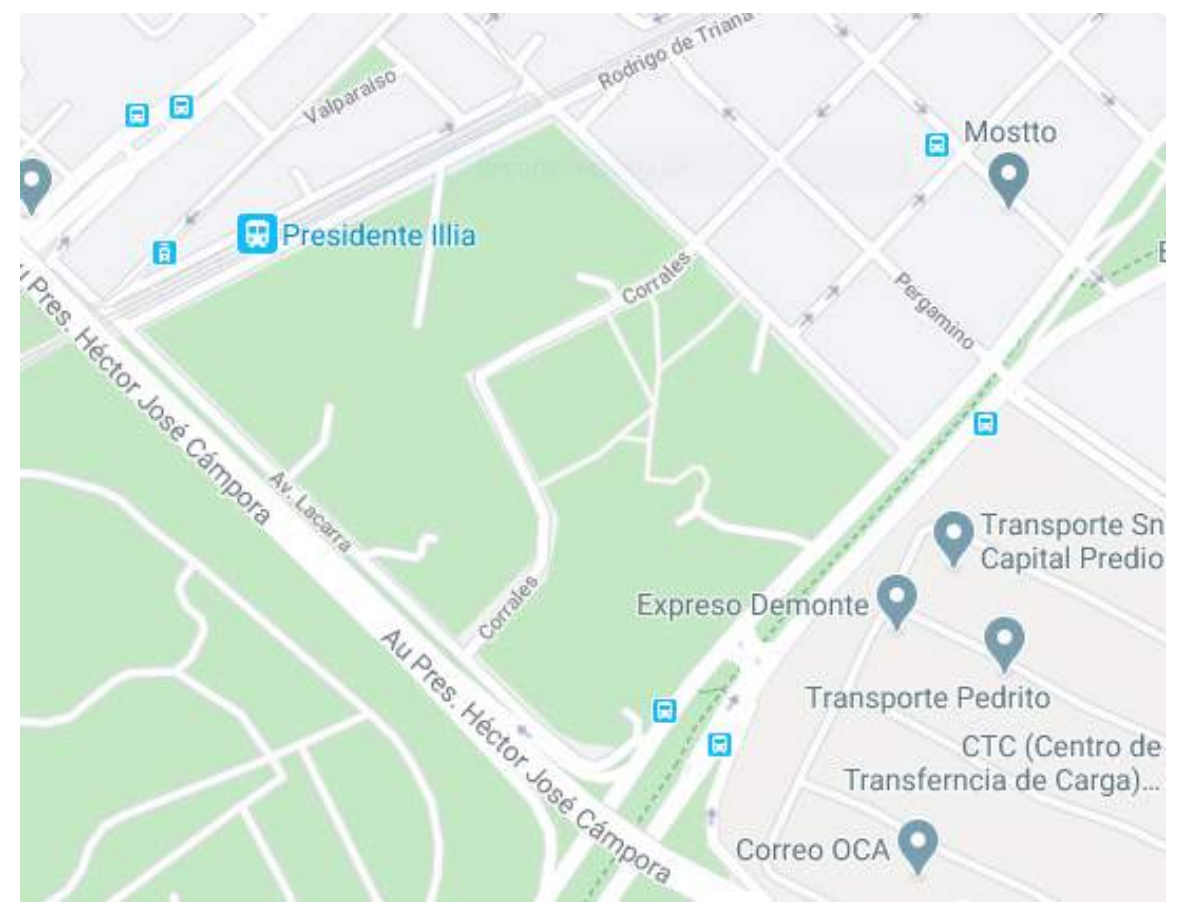

Fuente: GoogleMaps. 
El autor establece tres puntos claves en la intervención de la distorsión: la escala, la proyección y simbolización. Al igual que en la diagramación de una nueva ciudad, la confección de la cartografía no es ingenua: posee un alto contenido político y arbitrario.

Como se puede observar en la imagen 6, el predio en el que los complejos están construidos aparece en color verde. Icónicamente, ese color hace referencia a los espacios verdes, lugares para la dispersión/ recreación y/o plazas. Sin embargo, si contraponemos esta imagen cartográfica a la toma satelital (ver imagen 7) podemos evidenciar una gran diferencia:

Imagen 7. Imagen Satelital de los CHS.

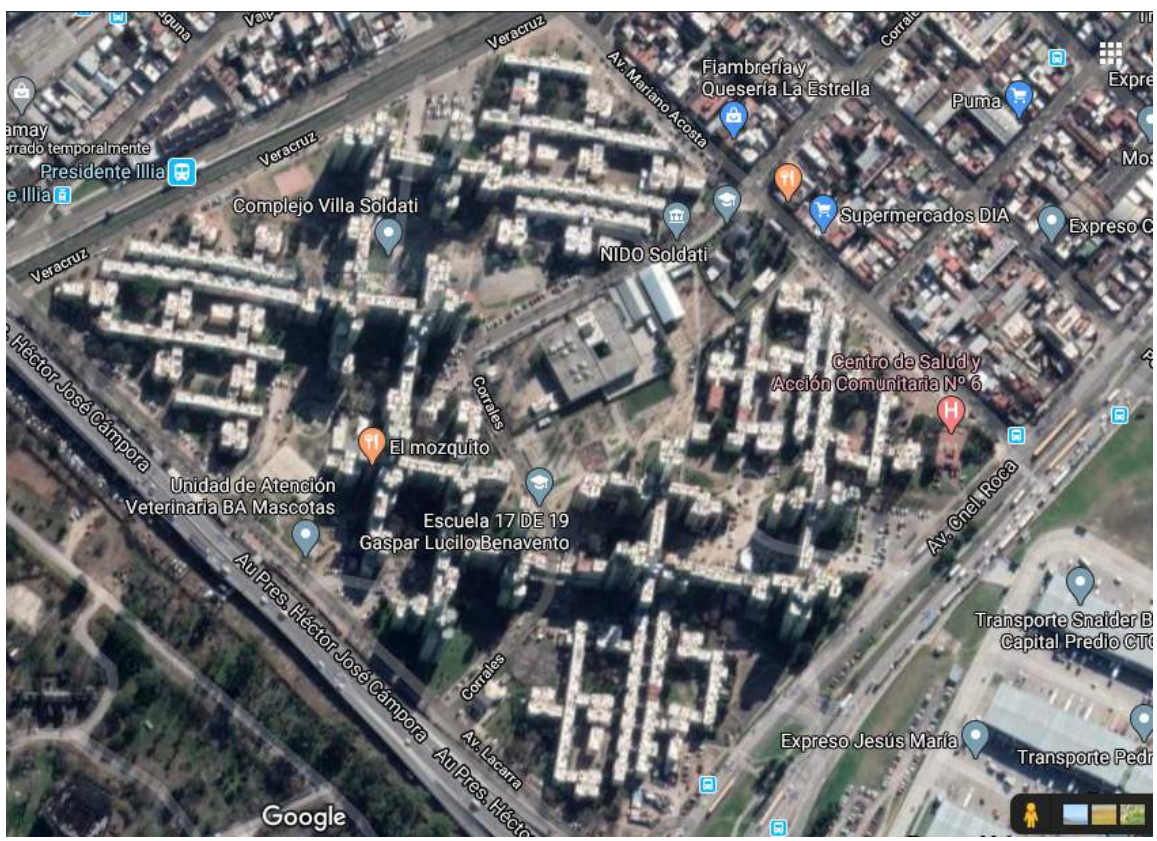

Fuente: GoogleMaps. 
A partir de contraponer ambas imágenes, podemos acercarnos a la idea que intento transmitir. En el predio delimitado por las calles Veracruz (al norte), Lacarra (al oeste), Av. Roca (al sur) y Mariano Acosta (al este) están los "edificios de colores", los cuales se encuentran separados por playones (que oscilan entre el cemento y algunos espacios verdes) pero lejos están de corresponder a un centro de deporte, recreación/ esparcimiento o a una plaza.

Otro de los detalles que hacen a esta impronta muy propia de Villa Soldati, son las longitudes de las cuadras o manzanas. Se puede observar que varias de ellas ocupan más de 100 o 150 metros (promedio estimado de las manzanas en $(A B A)$, lo cual le da una impresión distintiva.

Imagen 8. Captura de pantalla y medición de distancia.

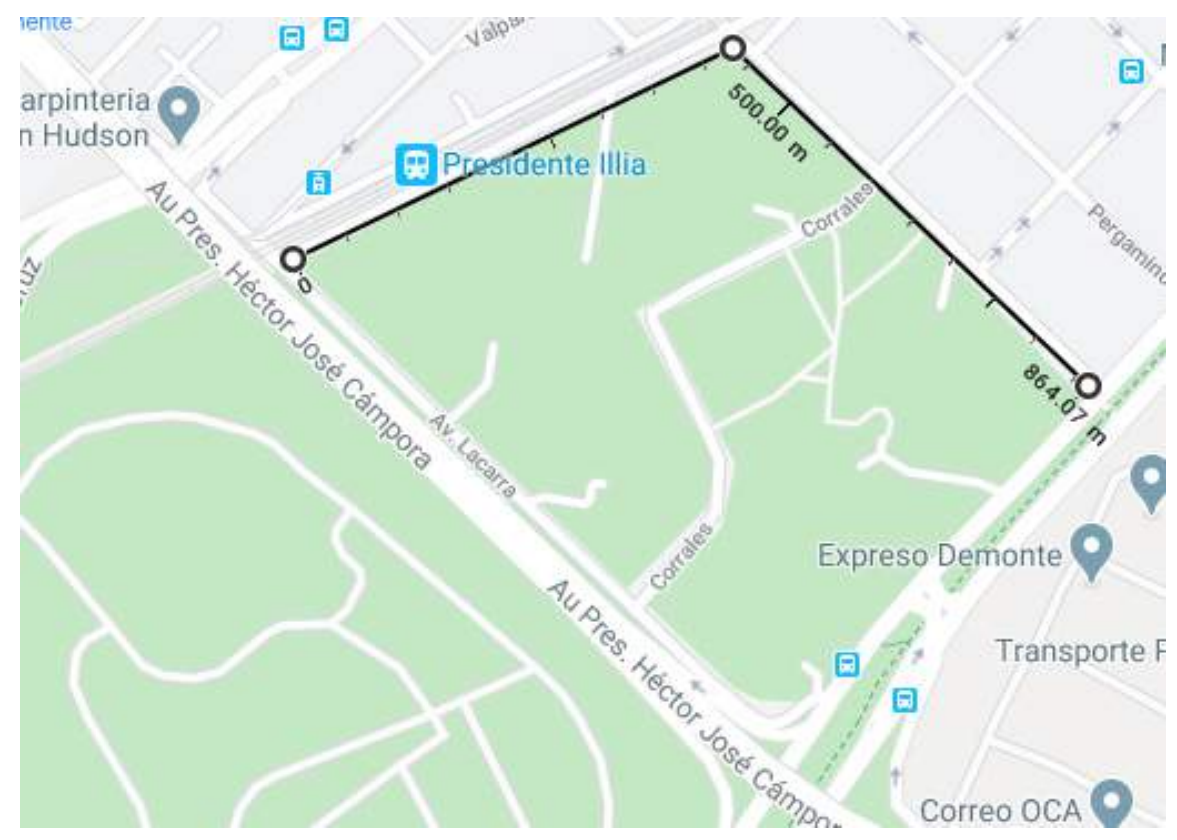

Fuente: GoogleMaps. 
Un breve recorrido visual nos hará adentrarnos en la idea. Como se puede observar en la imagen 8 , el lado norte del perímetro de los $\mathrm{CHS}$ es de unos 400 metros aproximadamente y el lado este es de 460 metros aproximadamente. Estas medidas dan cuenta de la extensión de las cuadras mencionada anteriormente. Si a esto le sumamos el paisaje cotidiano, es decir, cómo se habita y transita, se termina de contrastar esta "distorsión" que menciona Santos (ver imágenes 9, 10, 11 y 12).

Imagen 9. Mariano Acosta y Av. Roca.

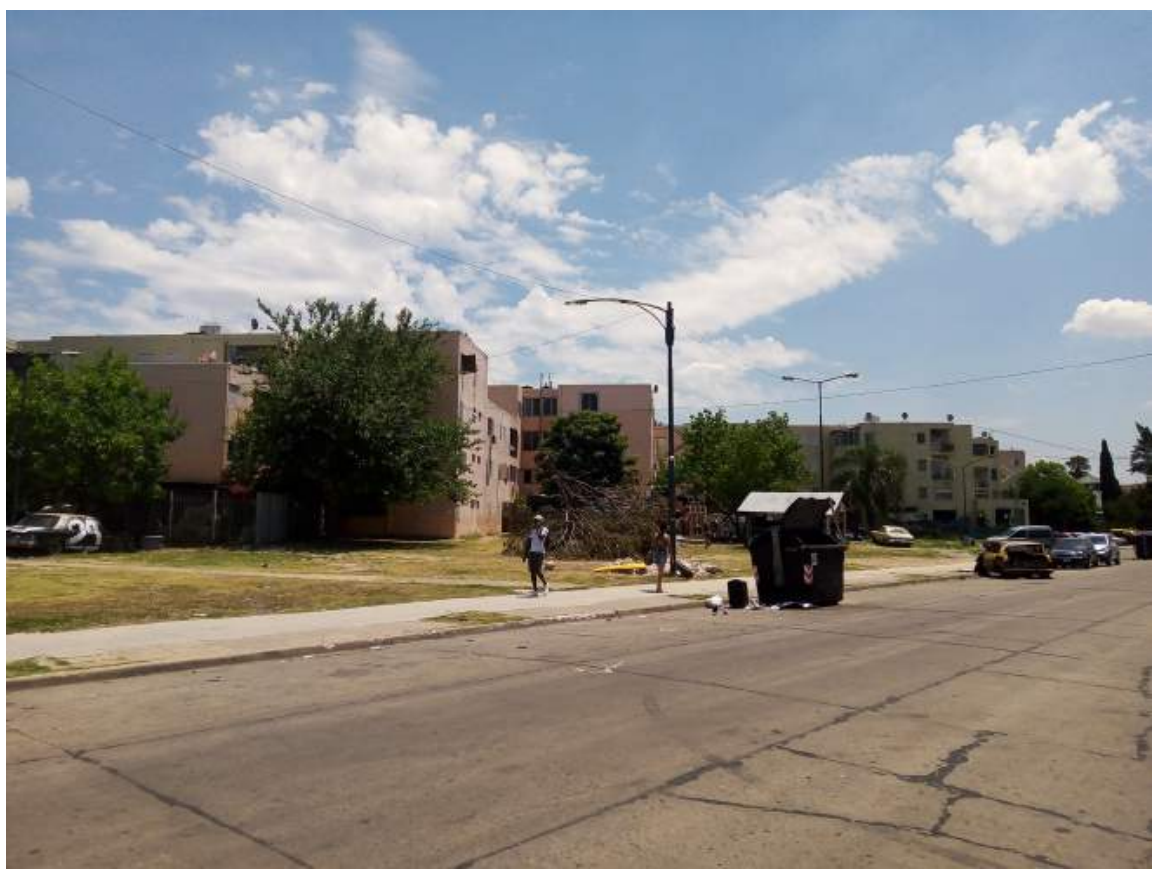

Fuente: Elaboración propia. Tomada en diciembre de 2019. 
Imagen 10. Mariano Acosta y Tabaré.

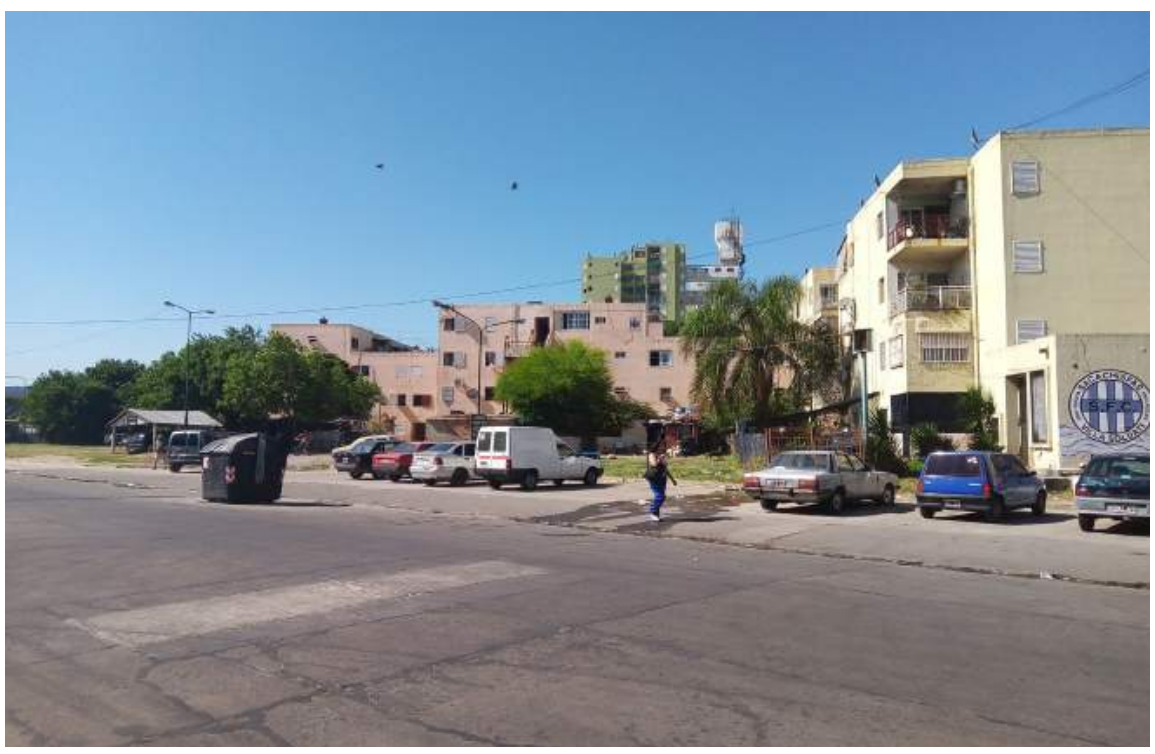

Fuente: Elaboración propia. Tomada en diciembre de 2019.

Imagen 11. "Pasaje interno de los CHS". Calle Veracruz (Lado Norte).

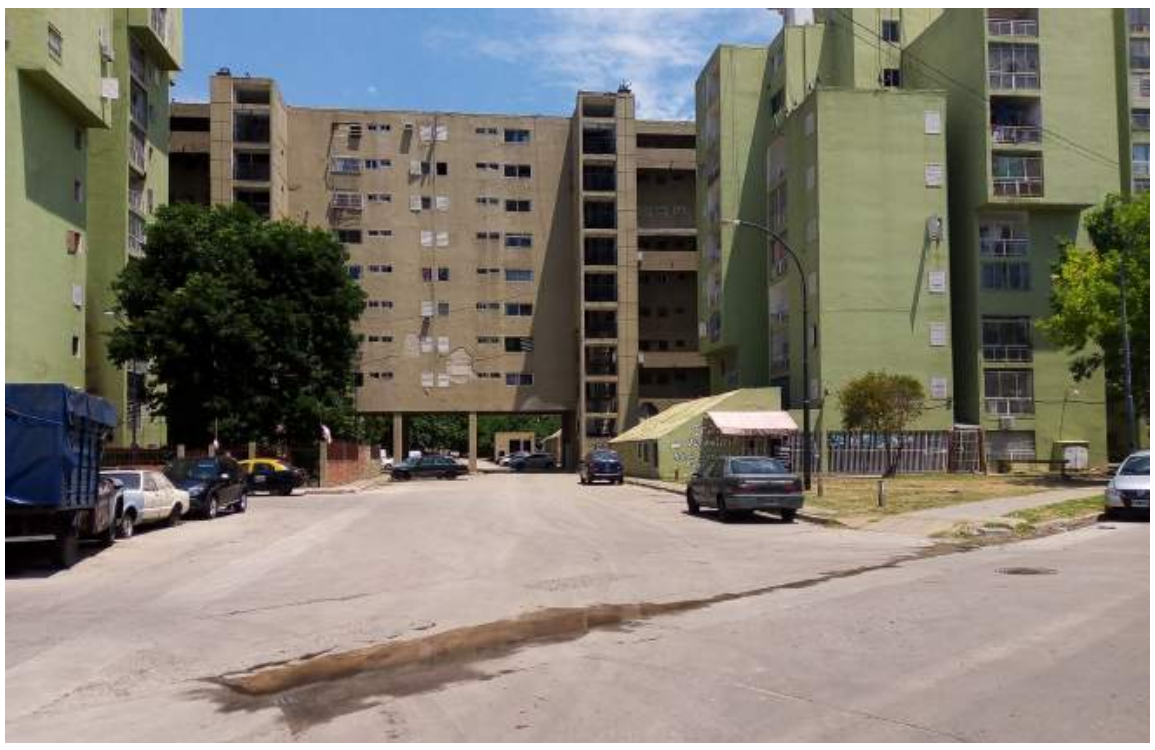

Fuente: Elaboración propia. Tomada en diciembre de 2019. 
Imagen 12. "Canchita de Futbol". Calle Veracruz.

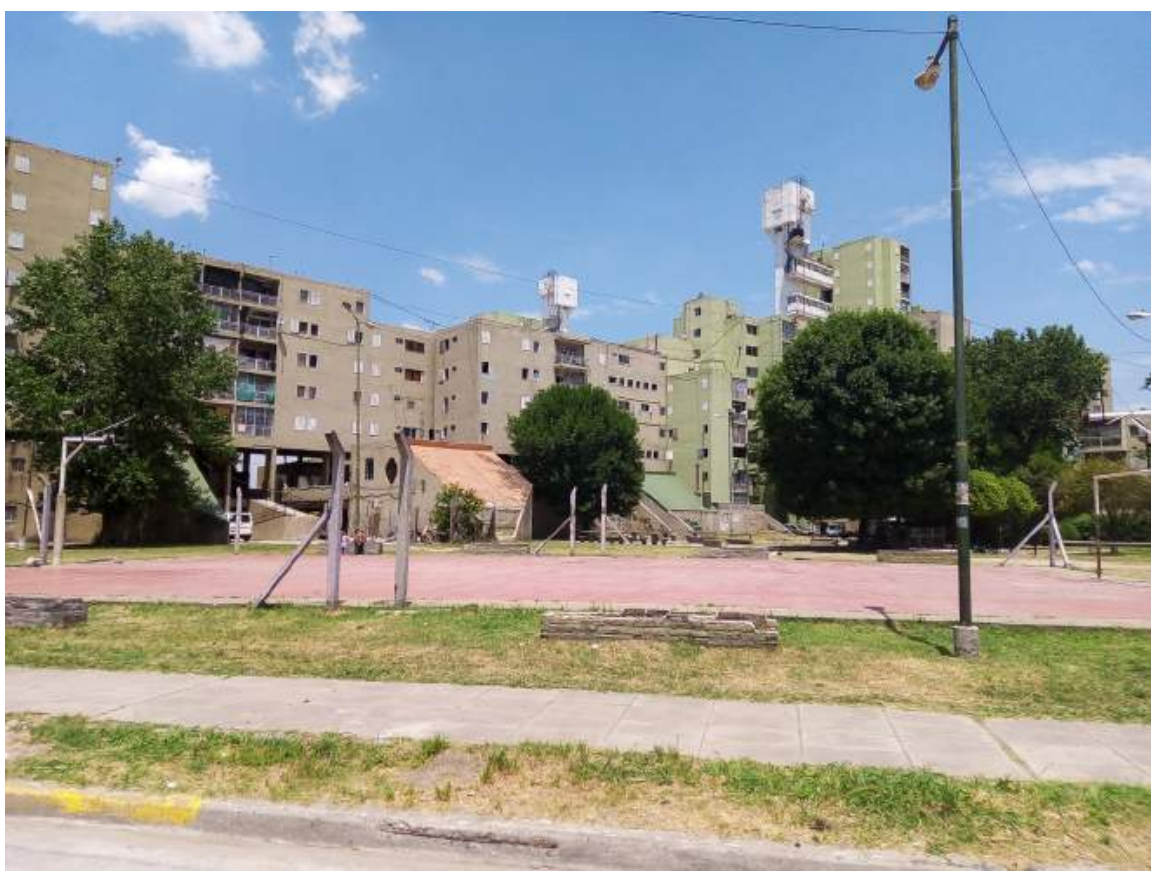

Fuente: Elaboración propia. Tomada en diciembre de 2019.

A este escenario se le suma el trazado de las calles: las mismas no permiten acceder a la totalidad de las superficies, generando de esta manera esos grandes bloques de aceras vacíos, que impiden la circulación de automóviles y desalientan la de los peatones.

El contraste que existe entre el espacio planificado -cartografíay el espacio que se habita o transita, es múltiple. No sólo se trata de la extensión de las veredas y las calles del complejo, sino que se tiñe con la particularidad de espacios desolados, sin tránsito de personas en las veredas mismas donde se encuentran los edificios, trayéndole una especie de "fantasmagoría" al escenario en pleno día:

En cuanto sirve para medir entre intención y acción, el mecanismo de la escala también se aplica a la acción social (...) El poder tiende a representar la realidad social y física en una escala escogida por su capacidad para crear los fenómenos que maximizan las condiciones 
de reproducción del poder. La representación/distorsión de la realidad es un presupuesto del ejercicio del poder (Santos, 1991. P. 23).

Es justamente a partir de esta afirmación que me animo a entrelazar el fenómeno de la tipificación. Las características, adjetivos, valores y atributos que se le adjudican a determinados barrios $-\mathrm{y}$ su población- basándose en datos cualitativos no sólo arbitrarios, sino en la deformación de la acción depositada en ellos, es lo que conlleva a un estereotipo que tiene como objetivo un fin político: la concentración y la segregación como dos caras de una misma moneda. 


\section{GUETO: RESIGNIFICACIÓN DE UN PARADIG- MA DESDE UNA PERSPECTIVA POSMODERNA}

El gueto, históricamente, es relacionado con un espacio bien definido y con límites claros -aislado, en la mayoría de los casos. La población que allí reside se caracteriza en general por pertenecer a una etnia o religión, heredada o practicada, según el caso, o por poseer un rasgo distintivo en el color de piel.

Wacquant (2010) nos ofrece otra perspectiva sobre este concepto. En su libro Las Dos Caras de un Gueto aborda la temática contraponiendo el ejemplo del gueto negro en Chicago, EE.UU. y las banlieues parisinas. En el primer caso, lo desarrolla según la original denominación analizando el gueto negro, el cual se conforma a partir de una real limitación socioespacial a partir de lo racial. Esta segregación se da con límites claros y en los cuales el gueto queda instalado y funcionando como una isla literal, la cual se traduce a partir de códigos de transitar por lugares establecidamente permitidos, con el color de piel como pasaporte al resguardo dentro del mismo gueto, como así también el peligro y violencia por fuera de él.

La apuesta del autor es la otra cara que le atribuye al gueto. En su investigación en las periferias de París, no sólo establece los límites espaciales de esa población en los suburbios parisinos, sino que detalla además a los pobladores y la geografía espacial desde una perspectiva económica, cultural, social y de las políticas estatales que inciden en ella. Enfatiza las consecuencias que acarrea el aislamiento de una población, que no implica necesariamente establecer fronteras concretas y materiales, sino que puede tratarse de limitaciones dadas a partir de la fragmentación laboral, la recesión económica o la vulnerabilidad en el tejido social, que se va generando a partir de las políticas de expulsión.

En la obra Los Condenados de la Ciudad, Wacquant (2013) profundiza aún más este análisis. Detrás de esa diversidad se encuentran los ejes centrales de la vida cotidiana en esta nueva conformación de "gueto". Por un lado, la irregularidad territorial. El peso que se le atribuye a vivir en lugares alejados del centro de la ciudad, pero con connotaciones negativas, que retroalimentan el círculo de la expulsión y, a la vez, cómo esta dinámica incide fuertemente a la hora de la elaboración de una identidad colectiva. La corrosión que se instala en el tejido social, genera retracción entre los mismos habitantes que hacen a esas periferias, reproduciendo la expulsión entre ellos mismos. 
Es un trabajo dialéctico: por un lado, se requiere que haya determinados espacios que alberguen a esa población vulnerable, marginalizándola. Pero es la misma marginación la que produce el estado de vulnerabilidad. Según el autor, "se necesita descivilizar para demonizar" (Wacquant, L.2013. p.49) 


\section{DE PARIS A SOLDATI}

Desde mis incipientes pasos por los espacios aledaños al CHS, uno de los rasgos distintivos de mi experiencia -hasta el día de hoy- es el de hacerme sentir "extranjera". Interpreto que ese "adentro/afuera", "pertenecer/no pertenecer" al complejo, es parte de las características de ese ethos de ser de Soldati.

Esa identidad podría ser construida alrededor de esa cohesión interna que es alimentada por la expulsión y aislamiento que se vive hacia el barrio. Uno de los puntos claves en el desarrollo de un posible gueto es el fuerte rechazo del afuera para con esa población involuntariamente confinada en un sector determinado de la ciudad. Esa segregación genera a la vez un efecto centrífugo e identitario para con los vecinos de ese lugar, en términos de Wacquant (2010): “(...) [una] máquina de identidad colectiva propia" (135). Esa nueva categoría poblacional excluida, profundiza aún más esta distancia sociocultural, es decir, entre los residentes de ese espacio segregado respecto a los demás habitantes de la ciudad, causando de este modo un acercamiento entre los individuos del grupo confinado, aunándolos en una identidad propia y colectiva.

Este punto se puede ver reflejado en las voces de las dos vecinas entrevistadas. María hace mención a la "zona roja" como una forma de referirse a Soldati cuando intenta tomar un remis (auto particular similar a un taxi, suele ser una salida laboral informal para quienes tienen un vehículo y lo pueden utilizar para trabajar) de "afuera". Lo mismo sucede con Celeste, quien trae el recuerdo de su adolescencia: "me pasaba que invitaba a alguna amiga, que vivía por allá y le decía que vivía en los edificios y era como "no, no, mi mamá dice que vengas a mi casa" [risas]. No era que no me querían a mí, sino que no querían entrar al barrio". Y refuerza ese valor que se le adscribe a la calle Mariano Acosta como función de "frontera" que marca la diferencia de "el barrio" del resto de Soldati.

Sin embargo, la propensión a la construcción de una identidad propia puede entrar en tensión con lo aportado por Celeste y María en las citas respectivas., cuando afirman que entre los mismos vecinos del complejo existen recelos y estigmatizaciones:

"Los vecinos de Soldati son raros igual (...) son medio de estigmatizar también." (Celeste) 
"Ahora no. Muy distinto. Ahora tenés que tener con llave todo" (María).

En estas afirmaciones se puede apreciar la tensión y contradicción en la constitución de la identidad colectiva. Si bien la población que vive en el CHS de alguna manera teje esa identidad compartida de recibir el estigma y la segregación desde el "afuera", a la vez esa misma expulsión y crítica se lleva a cabo entre los mismos vecinos. Se corrobora la afirmación de Weber (citado en Wacquant, 2010, p. 136) cuando dice que existe "una tendencia a fomentar entre sus miembros sentimientos de duda y odio hacia sí mismos."

Según los relatos de las entrevistadas, esta identidad estigmatizada comenzó a tener vigencia hace poco más de 15 años. Ambas coinciden en que esta construcción y connotación negativa sobre el barrio y su población comenzó a darse poco más de una década atrás. María agrega: "Hay mucha gente nueva. Mucha, pero mucha gente nueva. Muy poca la gente que quedó en el edificio mío que hace de 40 años".

También se puede resaltar en ellas la "romantización". En María se destaca un halo de nostalgia a lo largo de toda la entrevista. A medida que íbamos profundizando en la charla, su rostro iba cambiando y se esbozaba una sonrisa cuando recordaba aquellos años; así también el desaliento cuando caracterizaba el barrio hoy en día.

Ambas coinciden en la diferencia que evidencian con respeto al uso del espacio público, la vivencia de la vecindad de mutua colaboración, la solidaridad, el juego y el encuentro, entre ese pasado y el presente. En palabras de María, cuando le pregunto si nota cambios en el barrio desde que ella se mudó:

Sí, totalmente. Porque antes nosotros, salíamos a la tardecita. Salíamos a la noche a caminar por el barrio. Los bajitos ${ }^{8}$, y nosotros íbamos y caminábamos todo el barrio, todo espectacular. Ahora no podes salir. Para esta fecha [diciembre], un suponer, ponían todas luces, en todos los jardines. Ahora no. Todo cambió, Toda la gente cambió. Porque antes era una cosa que vos sacabas las sillas afuera, y te sentabas afuera con tu vecina de enfrente, tomabas mate. Ahora no. Muy distinto. Llegaba esta fecha [navidad] y la gente bajaba, 
qué se yo, brindaban. Tenías la puerta abierta, te saludaban. Era otra cosa [halo de nostalgia en la voz], te ponían campanitas en la puerta, las cuidaban. Los chicos tenían otro lugar. No sé. El vecino de arriba bajaba y brindaba con vos. Distinto, con las puertas abiertas, te digo que eso, se perdió [pausa] se perdió todo [hace un ademán con las manos, como indicando que se acabó] (María).

A la misma pregunta Celeste aporta:

¡Un montón! Yo vivía en la calle. Podía estar en la calle, tenía 8 o 9 años y podía estar jugando con mis amigos y bajaba a jugar como cualquiera que salía a la vereda a jugar. Bueno... hoy no lo dejaría bajar a Benja (su hijo) a jugar, qué se yo. Los fines de semana, bajaba a las 2 de la tarde y volvía a mi casa a las 7 de la tarde. No pasaba nada digamos. ¡Hoy! Puede ser que no pase nada [pausa] pero no sabés. Entonces, me da así como más cosa (Celeste).

Esta doblefuerzacentrífuga-opuesta, peroa lavezcomplementariaes la base de esa identidad e identificación de los vecinos del barrio. Esta relación dialéctica es uno de los ingredientes que colaboran en la generación y sirven como insumo para la constitución del habitus, que en términos de Bourdieu es esa "...'estructura estructurada', capaz de operar como 'estructura estructurante': disposiciones incorporadas, durables, transferibles y transformables que le permiten al sujeto un conjunto de comportamientos y de actitudes al tiempo que circunscriben su margen de acción..." (Tovillas, P. en Bourdieu, 2013, p. 16)

A partir de esta afirmación se puede ensayar una aproximación de cómo las acciones, comportamientos, identificaciones y tensiones pueden derivarse de ese rechazo externo, pero que toman forma a partir de los cambios internos que el complejo fue sufriendo. Y cómo esas tensiones fueron interpelando de diversas formas a los habitantes de los edificios, en sus concepciones y subjetividades.

El ethos y el habitus no se pueden analizar e interpretar de forma independiente de los cambios suscitados en el CHS. Éstos son parte de una dinámica constante que se viene configurando al interior de los "edificios de colores", sostenida por la fuerte carga externa sobre ellos. Esta doble vía se ve retroalimentada -además de por la oleada poblacional arribada 
en los últimos 25 años-, por los efectos de las políticas económicas recesivas de la década del '90, que repercutieron en el cordón sur en general y en el complejo en particular.

(...) la mayoría son todos vecinos nuevos. Gente nueva (...) mucha gente que se tuvo que ir de donde estaba y terminó por venirse a vivir acá porque es más económico. Eso veo mucho". Y agrega: "muchos de los locales que estaban, ya hoy no lo están. Y muchos fueron tomados como vivienda. Y había peluquería, videos juegos, video club, bueno todo eso... Olvidate. Fue más o menos para la época de Menem? Yo tendría... 7, 8 y ahí empezaron a cerrar todos los locales, cuando nosotros empezábamos a bajar, nos juntábamos ahí, jugábamos y de a poquito fue cambiando. Primero fue un video club, después fue un almacén, después fue un kiosco y después, desapareció" (Celeste).

El derecho a la ciudad está directamente relacionado con la posibilidad de accesibilidad y movilidad, no sólo al centro de las metrópolis, sino también a puntos nodales de las urbes necesarios para la satisfacción de derechos. Si nos detenemos un momento a ver cuáles son las vías de acceso al centro, a sitios de interés, cultura, oficinas de la administración pública y hospitales, nos daremos cuenta que por las inmediaciones del CHS sólo pasan dos líneas de autobús. A 400 metros se encuentra la estación de tren Villa Soldati del Ferrocarril Belgrano Sur que conecta la localidad de Merlo, en el Gran Buenos Aires, con el barrio de Pompeya en CABA, el cual no llega a los puntos clave de la ciudad. Por la Avenida F. F. de la Cruz, que queda a 300-600 metros del complejo, pasan otras tres líneas de autobús y el premetro ${ }^{10}$.

Visibilizar las posibles líneas de conexión con el resto de la ciudad es clave para poder entender esta conformación y devenir de "gueto" que nos aporta Wacquant (2010). Igual de significativa es la percepción que se tiene acerca del funcionamiento interrumpido o la baja frecuencia de líneas de autobús y premetro en determinados horarios.

Una de las causas del aislamiento del CHS es la eliminación de recorridos que algunas líneas de autobús tenían trazadas en un pasado por dentro de ese predio. María hace énfasis en este cambio sustancial cuando indica que "pasaban líneas de colectivo por la puerta".

9. Presidente de la Argentina (1989-1995) (1995-1999)

10. Medio de transporte similar al tranvía que sólo tiene un recorrido, con dos ramales, abarcando una porción de la ciudad. Ocupa el tramo desde el medio sur bajo y oeste. 
La posibilidad/imposibilidad de articulación y acceso a los puntos de la ciudad donde se encuentran los centros administrativos es parte del engranaje de la inserción para hacer uso -o no- de la "plena ciudadanía", teniendo como contracara el estigma y la segregación como parte de esa lógica inmobiliaria capitalista de la que nos hablaba Harvey (2014).

Este aislamiento se caracteriza por elementos materiales concretos, como los escasos o nulos medios de transporte público, precarización e informalidad laboral -incrementada por el estigma que conlleva vivir dentro de un complejo habitacional-, falta de mantenimiento de las viviendas y sus servicios (ascensores, bombas de presión de agua, entre otras). Pero además, establece una corrosión en el transitar del hábitat, gestando también la des-habitación del mismo: "el papel del gueto como una incubadora y matriz simbólica para la producción de una identidad estigmatizada" (Wacquant, 2010, p. 128).

Para dejar asentado este ítem comparto un fragmento de Celeste, una de las entrevistadas, al referirse a la realidad de salir al mercado laboral de los vecinos cuando el domicilio que figura en el currículum vitae (CV) remite a determinadas coordenadas: "Armamos CV para ir a buscar laburo y no poníamos el 'edificio tal', porque ya sabían que vivías en un complejo de edificios y no te llamaban. Poníamos [calle] 'Roca', la altura de la calle, no poníamos ni entre qué calles ni el edificio, porque no te llamaban. Así, tal cual".

Este deterioro, fragmentación y aislamiento tiene sus piezas funcionando a la perfección en la totalidad del sistema. En el marco de este análisis, que lo vincula a la lógica mercantil y capitalista inmobiliaria dentro de las ciudades modernas, es clave la función de distorsión y deformación de los mapas, ocultando la realidad de la segregación y los estereotipos negativos que aíslan a los habitantes del barrio del resto de la ciudad. Todo este engranaje no funcionaría, tampoco, si no existiesen políticas públicas a través de las cuales se ejecutan las funciones de dominación y control del Estado. 


\section{LA INCIDENCIA DE LAS POLÍTICAS ESTATALES}

Para generar esa"estructura estructurante"de la que habla Bourdieu, pensar el rol del aparato estatal es fundamental. Es el guionista en la planificación y directrices para llevar a cabo este modelo universalizado de las ciudades modernas. Podrían establecerse, grosso modo, tres ejes relevantes a nuestro análisis para pensar las políticas públicas llevadas a cabo por las gestiones del PRO:

1. La implementación de los "Distritos Económicos" en la CABA, con su clara inserción en el cordón sur de la ciudad.

2. El alcance y oferta en materia de salud y educación por parte del Estado, como garante para la práctica de la plena ciudadanía.

3. El papel de los organismos gubernamentales, como el Instituto de Vivienda de la Ciudad (IVC) y la Secretaría de Hábitat e Inclusión (SECHI), como actores estatales con presencia en el territorio.

El establecimiento de los distritos económicos en la ciudad responde a la lógica de la gentrificación, comentada anteriormente.

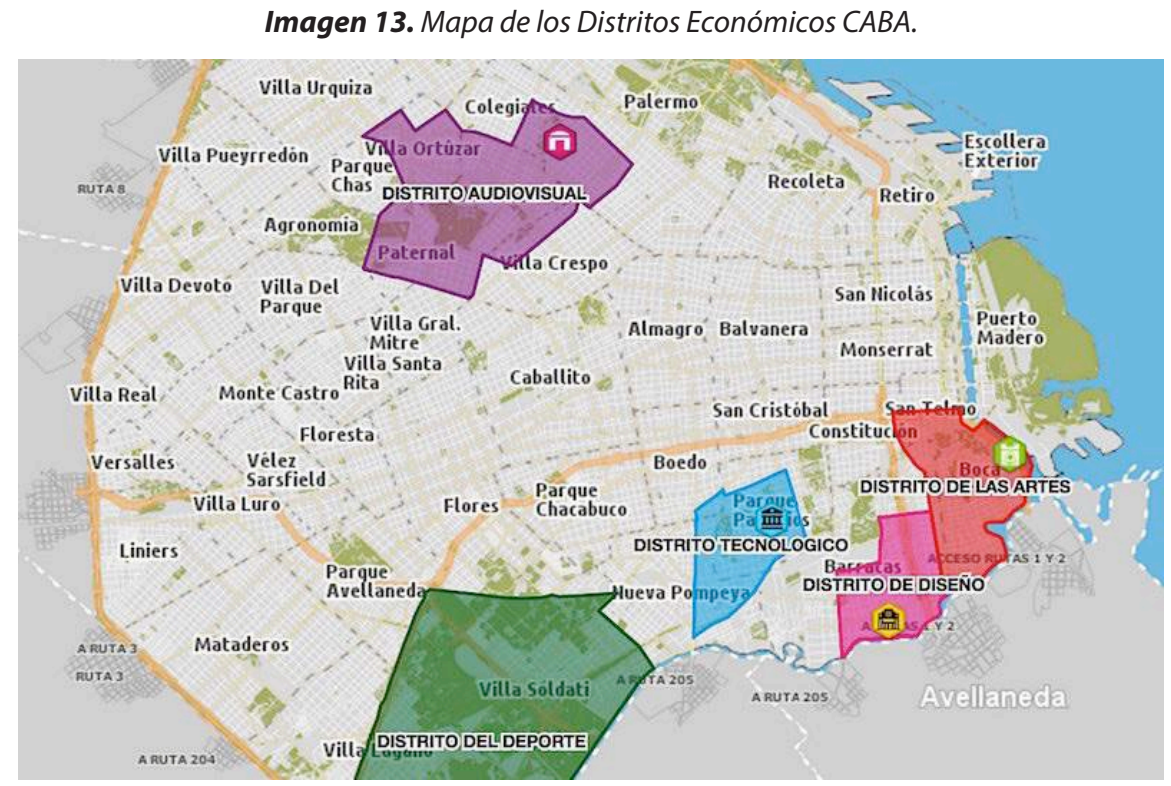

Fuente: Página Oficial del GCABA. 
Puede observarse en el mapa (imagen 13) que los distritos Tecnológico, Deportivo, de Diseño y Artes abarcan los barrios de Parque Patricios, Pompeya, Villa Soldati, Villa Lugano, parte del barrio de Flores, La Boca, Barracas y San Telmo, respectivamente. Estos últimos tres barrios, histórica y culturalmente, fueron receptores de oleadas migratorias, en distintos momentos del desarrollo de la ciudad. Si bien no resulta relevante para este trabajo desarrollar y caracterizar detalladamente el devenir en la configuración de cada barrio, sí resalto la dinámica socioespacial que se manifestó alrededor de ellos, como parte de esta planificación moderna. A lo largo de su historia, los barrios de La Boca, Barracas y San Telmo fueron testigos de cambios poblacionales, albergando a migrantes internos y extranjeros en su gran espectro habitacional conformado por conventillos, hoteles y pensiones que proliferaron a principios del siglo $X X$ y que, en menor medida, siguen vigentes hasta la actualidad.

La gestión del PRO -que va por su cuarto mandato consecutivo en la ciudad- llevó a cabo un proceso de rediseño del espacio público y privado, tejiendo en este proceso la expulsión, muchas veces mediante la violencia explícita de las fuerzas públicas, pero también mediante políticas de intimidación, alzas en los impuestos y servicios, todo acompañado de campañas de marketing que muestran estos procesos como un modo de "embellecer" la metrópolis. Es aquí cuando vemos en acción ese proceso de gentrificación en el que Harvey (2014) nos adentraba, y que posee su brazo ejecutor en el poder simbólico -anclado en lo material- que Santos denunciaba también. La expulsión de poblaciones con informalidad o vulnerabilidad habitacional, que fue relegada a la marginación, le dio lugar a los nuevos capitales inmobiliarios que no hicieron más que engrosar las arcas de los mismos inversionistas, cada vez más concentrados.

Con respecto al punto 2 , el acceso a la salud y educación es una de las condiciones sine qua non para practicar el derecho a la ciudad. Durante las gestiones de Mauricio Macri y Horacio Rodríguez Larreta en el gobierno de la CABA, desde 2007 al presente, se verificó una retracción constante en estas áreas. Un análisis del presupuesto destinado a salud y educación muestra que sólo entre 2013 y 2019, el presupuesto de salud se redujo en un 16,7\% en términos reales y el de educación en un 14,4\% (Fraschina, 2018). 
Asimismo, numerosas organizaciones de la sociedad civil vienen denunciando la falta de vacantes escolares para niños, niñas y adolescentes, especialmente infantes. Esta situación se agravó a partir del año 2014, cuando se implementó un sistema de inscripción escolar online: así, mientras en 2013 quedaron 6.767 alumnos y alumnas en lista de espera, en 2019 este número ascendió a 9.120 (Asociación Civil por la Inclusión y la Justicia, 2019). La implementación de este sistema online implicó también una barrera para muchos habitantes de las zonas más relegadas de la ciudad, donde la conexión a internet es precaria y no todas las familias disponen de los conocimientos y/o las herramientas materiales para acceder a estos servicios, dependiendo en muchos casos de la ayuda voluntaria que se les pueda ofrecer en diferentes espacios del barrio para poder acceder a la inscripción online.

Por la otra parte, la oferta de instituciones de salud estatal es escasa, sobre todo si se considera que muchas de ellas no tienen la infraestructura ni insumos para albergar casos de emergencias de agudos o nocturnos. Dentro de los límites del barrio Villa Soldati se encuentra el Centro de Salud y Atención Comunitaria (CeSAC) Nº, una sala de atención primaria, que está en las inmediaciones del CHS; el Centro Médico Cecilia Grierson, ubicado casi en el límite con Villa Lugano; y el CeSaC N²4 en el Barrio Carrillo (aledaño al Barrio Piletones) (Ver imagen 14) 
Imagen 14. Disposición de los CeSAC 6 y 24 y el Centro médico C. Grierson.

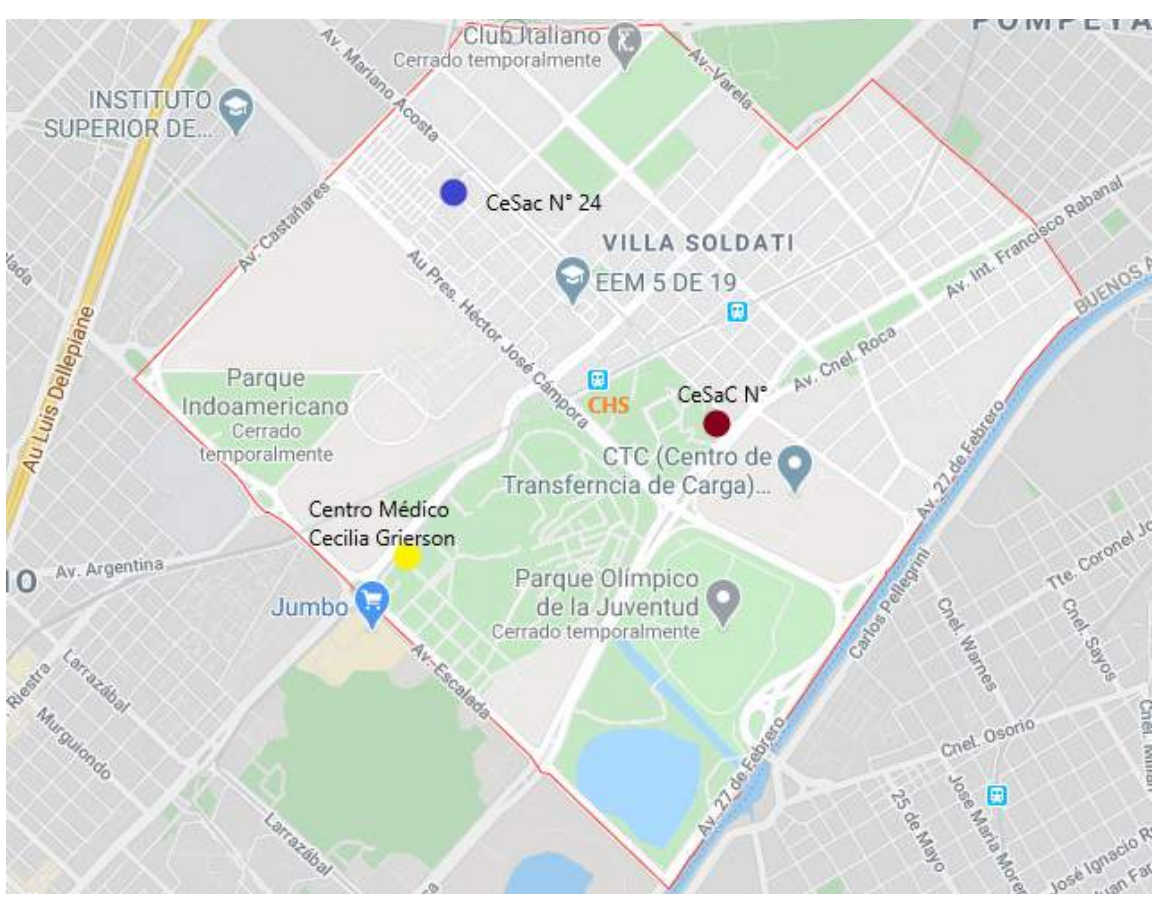

Fuente: GoogleMaps.

Los hospitales generales de agudos más cercanos son el Piñeiro y el Penna, en los barrios de Flores y Pompeya, a una distancia de entre 2.5 km y casi 4 km, respectivamente, tal como lo indica la imagen 15. 
Imagen 15. Distancia entre CHS y los hospitales Piñeiro y Penna.

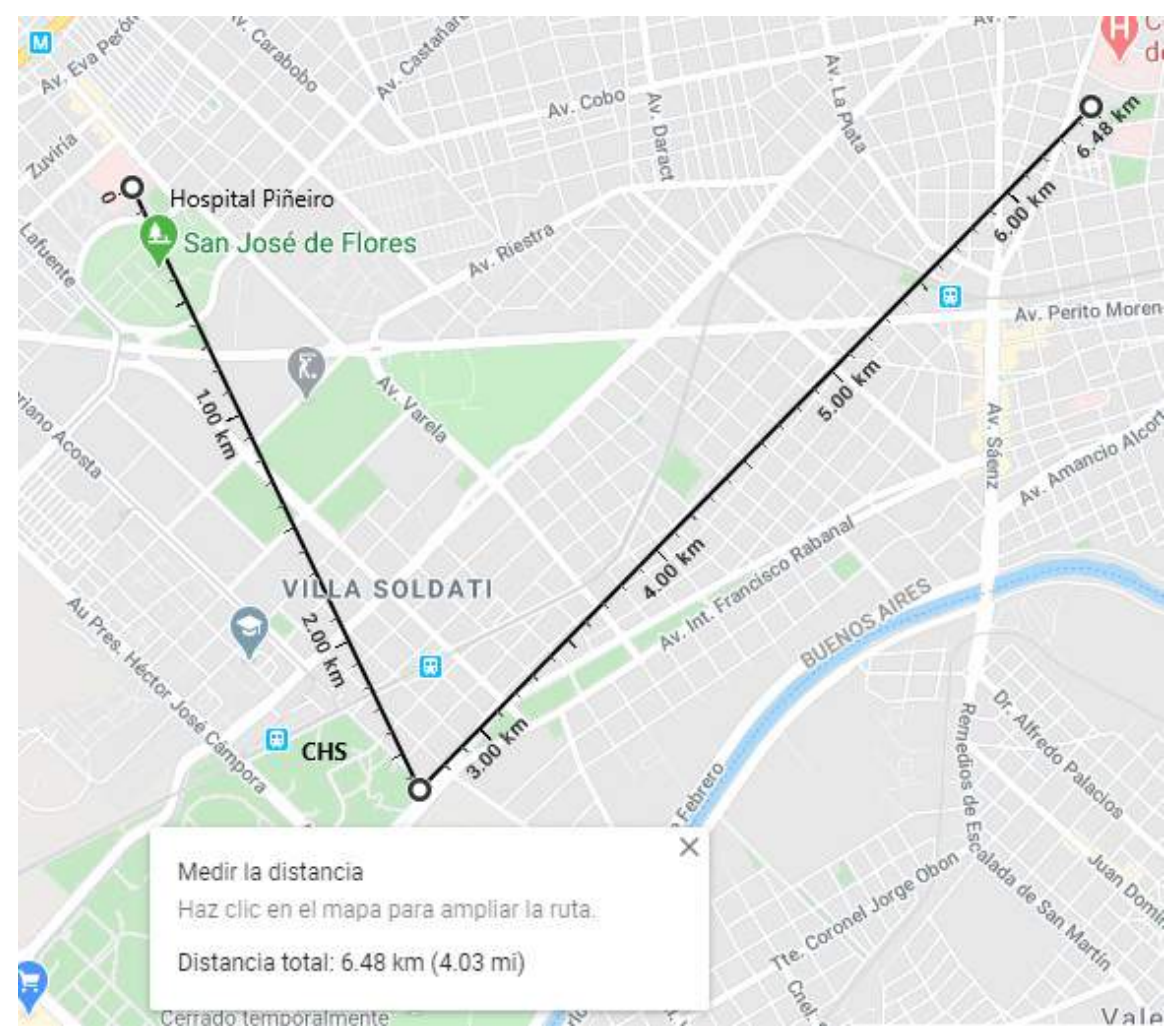

Fuente: GoogleMaps.

El CeSAC Nº, según los vecinos en general, y en la voz de María en particular, fue teniendo cada vez más restricciones en su funcionamiento, anulando especialidades y verificando una creciente escasez en los turnos programados. La entrevistada nos recuerda cómo era el funcionamiento de este centro de salud: "funcionaba, vos ibas a las 8 de la mañana y te atendían por orden de llegada. No tenías que ir a las 4/ 5 de la mañana a sacar turno. Ahora no, ahora ya cambió todo. Antes era distinto."

Las disrupciones en el funcionamiento de las instituciones generan conflictos que atentan contra la consecución de estos derechos. Por ejemplo, cuando los niños se enferman, muchas veces no pueden obtener el alta médica que se les solicita para poder volver a la escuela, 
debido al exceso de demanda en los centros de salud. Este vacío que se produce resulta en un modo de (no) ejecutar el acceso a la salud y educación como derechos básicos de los ciudadanos.

El tercer y último punto, pero no por ello menos importante, es el rol de los organismos estatales en el territorio. El IVC es el heredero de la Secretaría de la Vivienda y actual administrador del CHS. Ese rol incluye garantizar el mantenimiento de infraestructura, la ejecución de las escrituras y la garantía de la llegada de los servicios y funcionamiento de los ascensores. Si bien existe una administración propiamente dicha de los edificios, es el IVC el responsable supremo y garante de que todo ello esté asegurado. Claro está, que la debilidad de su presencia no es ingenua, sino que está directamente relacionada con el modus operandi y la perspectiva del modelo de ciudad y de ciudadanos que se tiene para con este tipo de población. Celeste nos aporta: "...empezaron a cerrar todos los locales (...) Hubo mucha gente viviendo ahora. Obviamente porque necesitan vivir en algún lado (...) lo que es a nivel, la fisonomía en general del barrio, sí, vinieron y pintaron. Lo que hacen cada 4 o 5 años"

En esta afirmación se deja entrever la ausencia concreta en materia de planificación y administración de los departamentos y espacios libres dentro del complejo por parte del IVC, como así también los retrasos y vericuetos para la ejecución de las escrituras.

En ese momento, a los 4 o 5 años vienen hacer un censo. Tenía a Benja bebé ${ }^{11}$, estaba viviendo mi viejo con nosotros todavía, ahí nos censan mi viejo jubilado, bueh....al tiempito, nunca llegó, como lo que siempre pasa en Soldati, no te llegan las boletas, no llega nada. A los 2 años, me entero como a los 2 años que tengo una deuda porque me había llegado ya para escriturar. Me presento, y la mina (mujer) que me atiende me dice "no, vamos a hacer todo de cero, porque este año vamos hacer un censo nuevo" y tuve la suerte de no tener que pagar esa deuda y empezar todo de nuevo. Y este año terminamos de pagar la escritura. Pero mirá cuántos años, como 7, 8 años (Celeste).

A María, por ejemplo, le otorgaron la escritura en el año 2017, es decir, casi 40 años después de estar viviendo en el complejo y pagando las cuotas del crédito, que inicialmente era a 30 años.

11. Benjamín es su hijo mayor. 
Por su lado, el nacimiento e inserción de la SECHI en las villas o conjuntos habitacionales para su inserción a la "trama urbana formal" 12 intenta ser un espacio de articulación del Estado con las organizaciones, agrupaciones y/o vecinos dentro de este tipo de asentamientos. La SECHI ofrece desde espacios de entretenimientos y espectáculos, talleres, gestiones culturales y la posibilidad de la inserción de los vecinos a la ciudad formal, hasta el acceso a puntos clave de la urbe mediante intervenciones en enseñanza de diversas disciplinas: danzas, deportes, artes visuales, excursiones, entre otras. Si bien existe un incentivo para recuperar las raíces propias tanto de los migrantes como del barrio, éste se basa en una frágil relación organismo-organizaciones, la cual se sustenta mediante un traspaso de dinero, pero que conlleva en general un retraso en los pagos, como así también una discrecionalidad en la división y participación de los vecinos en ella. En pocas palabras, sería un estilo de "maquillaje" superficial, alimentando este circuito marketinero del cual nació el partido del PRO en sí mismo, como así también sus políticas públicas y abriendo aguas entre el centro/norte de la ciudad y el sur de la misma, viéndose reflejado en este caso, entre los espectáculos para ciudadanos de "primera" y aquellos relegados para las periferias.

12. Término que aparece en la página oficial del Gobierno de la Ciudad de Buenos Aires. https://www.buenosaires. gob.ar/habitat/programas. 


\section{CONCLUSIONES}

A lo largo del presente trabajo, intenté dar cuenta, por un lado, de la interrelación que puede existir entre la construcción de un ethos que se crea dinámicamente a través de una fuerte expulsión social y política ajena al barrio, y por otro, de cómo el habitus que configura la estructura ajena, interpela a los vecinos del barrio haciendo que éstos incorporen como propias determinadas prácticas del "afuera", reproduciendo algunas de las matrices imperantes de estigmas y recelos.

Estas dinámicas están fuertemente atravesadas por una coyuntura mayor, relacionada con una estructura económica en recesión, la precariedad laboral que ello acarrea y la fragmentación entre los vínculos vecinales y barriales que conlleva a un ejercicio de retracción hacia los mismos habitantes del complejo, que no hace más que alimentar entre ellos los modelos de estereotipos y segregación.

Esta configuración socio-espacial incorpora los conceptos implícitos en el diseño y la producción de las ciudades modernas. La apropiación de estos códigos dominantes por parte de los habitantes del barrio los dota de técnicas, modos, habilidades; en síntesis, se construye ese habitus que les permite transitar y manejarse con determinados códigos dentro y fuera del barrio.

Tanto el habitus como el ethos son construcciones incorporadas no de manera consciente por los habitantes del barrio, sino que en la interacción entre ese "afuera" y "adentro" se van instalando modos y códigos que reproducen la estructura mayor y dominante. Sin embargo, como una habitante transitoria del barrio me es indispensable subrayar la distancia que marcan "los que pertenecen al barrio" de los que estamos de visita. Esa cualidad de extranjera, es una marca insoslayable y que se percibe como una barrera o frontera a la hora de circular por el barrio.

Es sumamente significativo y elemental resaltar la frase de Harvey (2014) cuando menciona que toda construcción de una nueva ciudad se da en base a la violencia. Esta aserción es la base de todo el trabajo. Son las lentes que acompañan cada acción programática que existe alrededor de cada política ejecutada dentro de los marcos de la gestión pública actual. De esta manera, queda en evidencia el lineamiento lógico llevado a cabo por la matriz de la elite inmobiliaria capitalista de la Ciudad Autónoma de Buenos Aires. 
La implementación de los distritos económicos puso en marcha el carrusel de las inversiones: comienza a subir el valor del suelo de espacios ociosos o desvalorizados, se abre la puesta de capitales para el alza del mismo, y como contracara se descarta lo que no sirve para el negocio. En la ecuación esencial de la gentrificación, lo único desechable son aquellos que no "entran" en la fórmula. Pero la violencia de la que nos hablaba Harvey (2014) no sólo se expresa mediante la fuerza física explícita, sino a partir de metodologías que inhiben las posibilidades de la inserción, inclusión y acceso.

Queda en evidencia así que el primer acto violento fue la reubicación desde 1978 de aquellas personas con situaciones habitacionales vulnerables, para luego ir sumándose otras líneas de acción. Entre ellas, la imposibilidad del acceso concreto a la salud y educación, como derechos básicos que debe garantizar el Estado, pero que en su funcionamiento real se vuelve expulsivo.

El rol de la geografía en fomentar la constitución de un gueto no es menor. La distancia real que existe entre la cartografía oficial y la real dinámica que existe en el barrio, no sólo retroalimenta esta idea de gueto y expulsión, sino que es el puntapié para la reproducción de la misma. La acción centrífuga que se da para con los sectores de la periferia, instalándolos -en términos de Girola (2007)- en una "ciudad dentro de otra ciudad", fue deviniendo en una segregación cada vez mayor.

Esas porosidades de las que nos habla la autora se pueden traducir en los límites tácitos que con el tiempo se fueron profundizando. Tales márgenes son descritos por las entrevistadas cuando hacen referencia a Mariano Acosta como una "frontera" entre el CHS y el resto del barrio; - María cuando hace mención al "adentro" (refiriéndose a los edificios) y el "afuera", como todo lo que es ajeno a él. Entre ambas dimensiones se establece una relación dialéctica y mutuamente constitutiva y es condición estructurada y estructurante del capital.

Esta dinámica e identidad se ve sostenida, de manera explícita, por medio de las políticas públicas actuales. Así lo ilustra, por ejemplo, la aseveración que se encuentra en la página oficial del Gobierno de la CABA, cuando se describe el objetivo del surgimiento y actual función de la SECHI: "Planifica e implementa intervenciones destinadas 
a la inclusión e integración urbana de las villas, impulsando proyectos urbanos participativos para la creación y recuperación de espacios en villas, núcleos habitacionales transitorios y conjuntos habitacionales" ${ }^{13 .}$

El ejercicio de interpretación está en resaltar lo explícito cuando hace referencia a la "inclusión e integración". La pregunta que me surge es: ¿por qué debe existir una secretaria que integre e incluya? Y la respuesta que me viene es: porque claramente no existe tal inserción ni inclusión a la ciudad. Es algo así como la resolución de la paradoja. Esta aserción deja al descubierto esa porosidad de la que Girola (2007) intenta dar cuenta en su trabajo.

A su vez, esta exclusión es compartida por gran parte de los vecinos del CHS, generándose así una aproximación a la existencia de ese ethos al que hago referencia renglones más arriba. Sin embargo, ese ethos que yo veo desde "afuera", se ve contradicho por la voz de las entrevistadas. Ambas, de manera contundente, aseguran que entre los mismos vecinos existe desconfianza, pero que la misma comenzó a surgir a raíz de cambios suscitados desde mediados de la década del '90. He aquí, una vez más, el impacto que marcaba antes en relación a la incidencia de los hechos coyunturales en el barrio. Por lo que, de alguna manera, existe esa corrosión que expuse a lo largo del artículo, en referencia a esa identidad colectiva intrínseca entre los mismos habitantes del complejo. Sin embargo, visto desde "afuera", suele suponerse la existencia de una identidad homogénea, lo cual condiciona a los habitantes del Barrio Soldati en sus posibilidades de acceso al derecho a la ciudad.

13. Gobierno de la Ciudad de Buenos Aires. Secretaria de Cultura, Hábitat e Inclusión, perteneciente al Ministerio de Desarrollo Humano y Habitat. https://www.buenosaires.gob.ar/habitat/programas 


\section{BIBLIOGRAFÍA}

ACUMAR (2019) Informe de Gestión de Casos Enero - Marzo 2019. Buenos Aires. Recuperado de http://www.acumar.gob.ar/ wp-content/uploads/2016/12/ANEXO-II-a-Trimestral-deGesti\%C3\%B3n-de-Casos-Enero-marzo-2019-2.pdf

Asociación Civil por la Inclusión y la Justicia (2019) La falta de inversión pública para resolver el problema de falta de vacantes en nivel inicial. Buenos Aires. Recuperado de: ttps://acij.org. ar/mas-de-9-mil-ninas-y-ninos-se-quedaron-sin-vacantesen-el-nivel-inicial-porteno/

Bourdieu, P. (2013) Argelia 60, estructuras económicas y estructuras temporales. Buenos Aires. Siglo XXI.

Bourdieu, P. (2003) Participan Objetivation. The Journal of the Royal Anthropological Institute, Vol 9, Nro 2 UK (traducción de Julieta Gaztañaga) pp 281-294.

Fraschina, S. (2018) Infografía Presupuesto CABA 2019. Universidad Nacional de Avellaneda. Recuperado de https://www.undav. edu.ar/general/recursos/adjuntos/22046.pdf

Girola, M. F. (2007) Procesos de apropiación del espacio y sociabilidad vecinal en un gran conjunto urbano situado en la ciudad de Buenos Aires, Publicación Antropológica, volumen $n^{\circ} \mathrm{XXV}$. pág. 131 a 155

Harvey, D. (2014) Ciudades Rebeldes. Del derecho de la ciudad a la revolución urbana. Buenos Aires. Ediciones Akal. 
Santos, B. (1991) Una cartografía simbólica de las representaciones sociales, Revista Nueva Sociedad, volumen n¹16, pág. 18 a 38.

Thomasz, A. G. y Girola, M. F. (2014). Políticas urbanas en Buenos Aires: una mirada etnográfica sobre la producción de complejos habitacionales. Cuadernos de Vivienda y Urbanismo, 7(14), 276-292. http://dx.doi.org/10.11144/Javeriana.CVU714.pubm

Wacquant, L. (2010) Las dos caras de un gueto. Ensayos sobre marginalización y penalización. Buenos Aires. Siglo XXI.

Wacquant, L. (2013) Los condenados de la ciudad. Gueto, periferias y Estado. Buenos Aires. Siglo XXI. 